\title{
Formation of secondary organic aerosol and oligomers from the ozonolysis of enol ethers
}

\author{
A. Sadezky ${ }^{1,2}$, P. Chaimbault ${ }^{3}$, A. Mellouki ${ }^{2}$, A. Römpp ${ }^{1}$, R. Winterhalter ${ }^{1}$, G. Le Bras ${ }^{2}$, and G. K. Moortgat ${ }^{1}$ \\ ${ }^{1}$ Max-Planck-Institute for Chemistry, Atmospheric Chemistry Department, P.O. Box 3060, 55020 Mainz, Germany \\ ${ }^{2}$ Laboratoire de Combustion et de Systèmes Réactifs, CNRS, 1C Avenue de la Recherche Scientifique, 45071 Orléans Cedex \\ 2, France \\ ${ }^{3}$ Institut de Chimie Organique et Analytique, UMR 6005, BP 6759, University of Orléans, 45067 Orléans Cedex 2, France
}

Received: 18 April 2006 - Published in Atmos. Chem. Phys. Discuss.: 29 June 2006

Revised: 20 October 2006 - Accepted: 20 October 2006 - Published: 31 October 2006

\begin{abstract}
Formation of secondary organic aerosol has been observed in the gas phase ozonolysis of a series of enol ethers, among them several alkyl vinyl ethers (AVE, $\mathrm{ROCH}=\mathrm{CH}_{2}$ ), such as ethyl, propyl, $n$-butyl, isobutyl, $t$-butyl vinyl ether, and ethyl propenyl ether (EPE, $\mathrm{C}_{2} \mathrm{H}_{5} \mathrm{OCH}=\mathrm{CHCH}_{3}$ ). The ozonolysis has been studied in a 5701 spherical glass reactor at ambient pressure (730 Torr) and room temperature $(296 \mathrm{~K})$. Gas phase reaction products were investigated by in-situ FTIR spectroscopy, and secondary organic aerosol (SOA) formation was monitored by a scanning mobility particle sizer (SMPS). The chemical composition of the formed SOA was analysed by a hybrid mass spectrometer using electrospray ionization (ESI). The main stable gas phase reaction product is the respective alkyl formate $\mathrm{ROC}(\mathrm{O}) \mathrm{H}$, formed with yields of 60 to $80 \%$, implying that similar yields of the corresponding excited Criegee Intermediates (CI) $\mathrm{CH}_{2} \mathrm{O}_{2}$ for the AVE and $\mathrm{CH}_{3} \mathrm{CHO}_{2}$ for $\mathrm{EPE}$ are generated. Measured SOA yields are between 2 to $4 \%$ for all enol ethers. Furthermore, SOA formation is strongly reduced or suppressed by the presence of an excess of formic acid, which acts as an efficient CI scavenger.

Chemical analysis of the formed SOA by ESI(+)/MS-TOF allows to identify oligomeric compounds in the mass range 200 to $800 \mathrm{u}$ as its major constituents. Repetitive chain units are identified as $\mathrm{CH}_{2} \mathrm{O}_{2}$ (mass 46) for the AVE and $\mathrm{C}_{2} \mathrm{H}_{4} \mathrm{O}_{2}$ (mass 60) for EPE and thus have the same chemical compositions as the respective major Criegee Intermediates formed during ozonolysis of these ethers. The oligomeric structure and chain unit identity are confirmed by HPLC/ESI(+)/MSTOF and ESI(+)/MS/MS-TOF experiments, whereby successive and systematic loss of a fragment with mass 46 for the AVE (and mass 60 for EPE) is observed. It is proposed that the oligomer has the following basic structure of an oligoperoxide, $-[\mathrm{CH}(\mathrm{R})-\mathrm{O}-\mathrm{O}]_{\mathrm{n}^{-}}$, where $\mathrm{R}=\mathrm{H}$ for the $\mathrm{AVE}$ and $\mathrm{R}=\mathrm{CH}_{3}$
\end{abstract}

Correspondence to: A. Mellouki

(mellouki@cnrs-orleans.fr) for the EPE. Oligoperoxide formation is thus suggested to be another, so far unknown reaction of stabilized Criegee Intermediates in the gas phase ozonolysis of oxygen-containing alkenes leading to SOA formation.

\section{Introduction}

Alkyl vinyl ethers are increasingly produced as solvents to be used in the chemical industry. Because of their reasonable volatility this class of compounds will result in a significant emission into the urban atmosphere. Consequently alkyl vinyl ethers will be oxidized by $\mathrm{OH}-$ and $\mathrm{NO}_{3}$-radicals and $\mathrm{O}_{3}$.

A few investigations have recently been reported on the kinetics and product distribution of simple alkyl vinyl ethers. Thiault et al. (2002) studied the $\mathrm{OH}$ and $\mathrm{O}_{3}$ initiated oxidation of ethyl vinyl ether $\left(\mathrm{EVE}, \mathrm{C}_{2} \mathrm{H}_{5} \mathrm{O}-\mathrm{CH}=\mathrm{CH}_{2}\right)$. The main products from both reactions were formaldehyde and ethyl formate $\mathrm{C}_{2} \mathrm{H}_{5} \mathrm{OC}(\mathrm{O}) \mathrm{H}$. Additional studies performed in the EUPHORE chamber revealed the formation of secondary organic aerosols (SOA) (George et al., 2005).

Klotz et al. (2004) performed a product study of the gasphase reactions of $\mathrm{O}_{3}, \mathrm{OH}$ and $\mathrm{NO}_{3}$ with methyl vinyl ether (MVE, $\mathrm{CH}_{3} \mathrm{O}-\mathrm{CH}_{2}=\mathrm{CH}_{2}$ ). The main products from all reactions were formaldehyde and methyl formate $\mathrm{CH}_{3} \mathrm{OC}(\mathrm{O}) \mathrm{H}$; in the case of the $\mathrm{O}_{3}$ reaction, hydroperoxymethyl formate, methanol, $\mathrm{CO}_{2}$ and $\mathrm{CO}$ were also produced. Interestingly, particle formation was observed in the ozonolysis, but not in the $\mathrm{OH}$ or $\mathrm{NO}_{3}$ radical reactions. The mean size of the particles measured at the end of the experiment ( 1 to $3 \mathrm{~h}$ ) was typically $60 \mathrm{~nm}$ in diameter. Methyl vinyl ether with only three carbon atoms, is the smallest compound studied that produces aerosol during its atmospheric degradation. Usually, seven or more $\mathrm{C}$ atoms are required from non-cyclic hydrocarbons, six from cyclic species to initiate SOA formation (Seinfeld and Pankow, 2003; Seinfeld and Pandis, 1998).

Published by Copernicus GmbH on behalf of the European Geosciences Union. 
A detailed investigation of the ozonolysis of six unsaturated alkyl ethers has been performed in a laboratory reaction chamber: ethyl vinyl ether (EVE), ethyl propenyl ether (EPE), propyl vinyl ether (PVE), $n$-butyl vinyl ether (BVE), $t$-butyl vinyl ether (TBVE), and $i$ so-butyl vinyl ether (IBVE). Gas phase products have been quantified by FTIR spectroscopy and SOA have been observed by a SMPS system and characterized by an HLPC coupled to a hybrid mass spectrometer (Sadezky, 2005). This paper reports the formation and identification of a series of oligomeric products in the ozonolysis of all the studied unsaturated alkyl ethers.

\section{Experimental}

Experiments in the laboratory were performed in a 570-liter spherical glass reactor at room temperature in synthetic air at a total pressure of 730 Torr. A detailed description of this setup has been described in earlier publications (Neeb et al., 1998; Winterhalter et al., 2000). Ozone was produced by a mercury pen-ray lamp inside the reactor, prior to the addition of the mixture of vinyl ether and synthetic air (reaction start). The concentrations of reactants and reaction products were followed by Fourier Transform infrared spectroscopy (FTIR). The aerosol concentration and size distribution was monitored with a scanning mobility particle sizer (SMPS, TSI 3936). The SMPS consists of an electrostatic classifier (TSI 3080) with a long differential mobility analyzer, (LDMA; TSI 3081) and an ultrafine condensation particle counter (CPC; TSI 3025A) as detector.

Experiments were performed with initial ether mixing ratios varying between $200 \mathrm{ppb}$ and $9 \mathrm{ppm}$, and similar or slightly lower ozone mixing ratios. For the studies involving observation of SOA formation profiles, mixing ratios between 200 and $400 \mathrm{ppb}$ of ether and ozone were used, whereas for experiments with chemical analysis by mass spectrometry of collected aerosols, $8 \mathrm{ppm}$ of ozone and $9 \mathrm{ppm}$ of ether were used. In order to prevent reactions of vinyl ethers with $\mathrm{OH}$ radicals, which are known to be generated during the ozonolysis of alkenes (Finlayson et al., 1972), cyclohexane (excess, $300 \mathrm{ppm}$ ) was added in some experiments. In another type of experiments, excess $\mathrm{HCOOH}$ (20 ppm) was added as scavenger for stabilized Criegee Intermediates. All chemicals were commercially available (purity $>95 \%$ ) and used without further purification.

The aerosol formed in the laboratory experiments was collected during 20 to $25 \mathrm{~min}$ on Teflon (PTFE) filters ( $45 \mathrm{~mm}$ diameter, $0.45 \mu \mathrm{m}$ pore size), using a flow rate of $14 \mathrm{~L} \mathrm{~min}^{-1}$. After collection the filters were extracted in a $7 \mathrm{~cm}^{3}$ glass flask with $3 \mathrm{ml}$ pure methanol (HPLC grade), and stored at $-20^{\circ} \mathrm{C}$ until analysis.

For chromatographic separation, $10 \mu \mathrm{L}$ of this extract were directly injected into the HPLC system, which consisted of a thermostated autosampler (Series 200, Perkin Elmer), a degasser and a quaternary pump (both
1100 Series, Agilent Technologies). The analytical column $(250 \mathrm{~mm} \times 2 \mathrm{~mm}$ I.D., $5 \mu \mathrm{m}$ particle size $)$ contains a ReproSil-Pur $\mathrm{C}_{18}$-AQ stationary phase (Dr. Maisch GmbH). The eluents were $0.1 \%$ formic acid in deionized water (eluent A) and acetonitrile (HPLC-grade) (eluent B). The gradient of the mobile phase was as follows: $0 \% \mathrm{~B}$ for $0.5 \mathrm{~min}$, gradient to $15 \% \mathrm{~B}$ in $2.5 \mathrm{~min}$, gradient to $100 \% \mathrm{~B}$ in $16 \mathrm{~min}$, isocratic for $6.5 \mathrm{~min}$. The flow of the mobile phase was $400 \mu \mathrm{L} / \mathrm{min}$.

Chemical constituents were detected by a hybrid mass spectrometer (quadrupole and time-of-flight) QSTAR (Applied Biosystems MDS SCIEX) with an electrospray ion source. The extraction solution was either directly injected ( $10 \mu \mathrm{L} / \mathrm{min}$ ) or previously separated by HPLC as described before. The electrospray ion source (TurboIonSpray) was operated in the positive mode at $400^{\circ} \mathrm{C}$ and an ionization voltage of $+3.4 \mathrm{kV}$. The declustering potential was $+30 \mathrm{~V}$, and the focussing potential (focus ring) was $+100 \mathrm{~V}$. For tandem QTOF experiments, the collision energy was between 15 and $30 \mathrm{eV}$ with CAD (collision gas) set to 2 . Instrument control, spectra treatment and calculations of elemental compositions were done with the software Analyst (Applied Biosystems MDS SCIEX). Further instrumental and analytical details are reported by Römpp (2003).

\section{Results}

3.1 General aspects and gas phase mechanism of the ozonolysis of enol ethers

The general mechanism of the ozonolysis of unsaturated ethers is displayed in Fig. 1. The initial product formed is the primary ozonide (1,2,3-trioxolane), which is unstable and decomposes into a carbonyl oxide, called the Criegee Intermediate (CI), and a primary carbonyl compound. The ozonolysis of the ether molecules investigated in this study produces $\mathrm{CIs}$ of the type $\mathrm{CH}_{2} \mathrm{OO}\left(\mathrm{C}_{1}-\mathrm{CI}, \mathrm{R}^{\prime}=\mathrm{H}\right)$ for the alkyl vinyl ethers (AVE), and $\mathrm{CH}_{3} \mathrm{CHOO}\left(\mathrm{C}_{2}-\mathrm{CI}, \mathrm{R}^{\prime}=\mathrm{CH}_{3}\right)$ for ethyl propenyl ether (EPE), together with ROCHOO (alkoxysubstituted CI). The $\mathrm{R}$ group consists of $\mathrm{C}_{2} \mathrm{H}_{5}$ for EVE and $\mathrm{EPE}, \mathrm{C}_{3} \mathrm{H}_{7}$ for PVE and $\mathrm{C}_{4} \mathrm{H}_{9}$ for the three different butyl vinyl ethers. The corresponding primary carbonyl compounds consist of an alkyl formate and formaldehyde or acetaldehyde. The CIs formed from the decomposition of the primary ozonide are formed in excited states, which then either decompose into various products or become collisionaly stabilized. Nearly half of the excited CIs are stabilized, and it has been established that stabilized CIs (SCIs) undergo in the gas phase a variety of bimolecular reactions with carbonyl compounds, $\mathrm{HCOOH}$ and $\mathrm{H}_{2} \mathrm{O}$ to form secondary ozonides (1,2,4-trioxolanes), hydroperoxy formates and hydroxyhydroperoxides, respectively (Calvert et al., 2000).

The yields of the different gas phase products have been determined by FTIR spectroscopy for EVE and EPE, from which the branching ratio of the splitting of the primary 


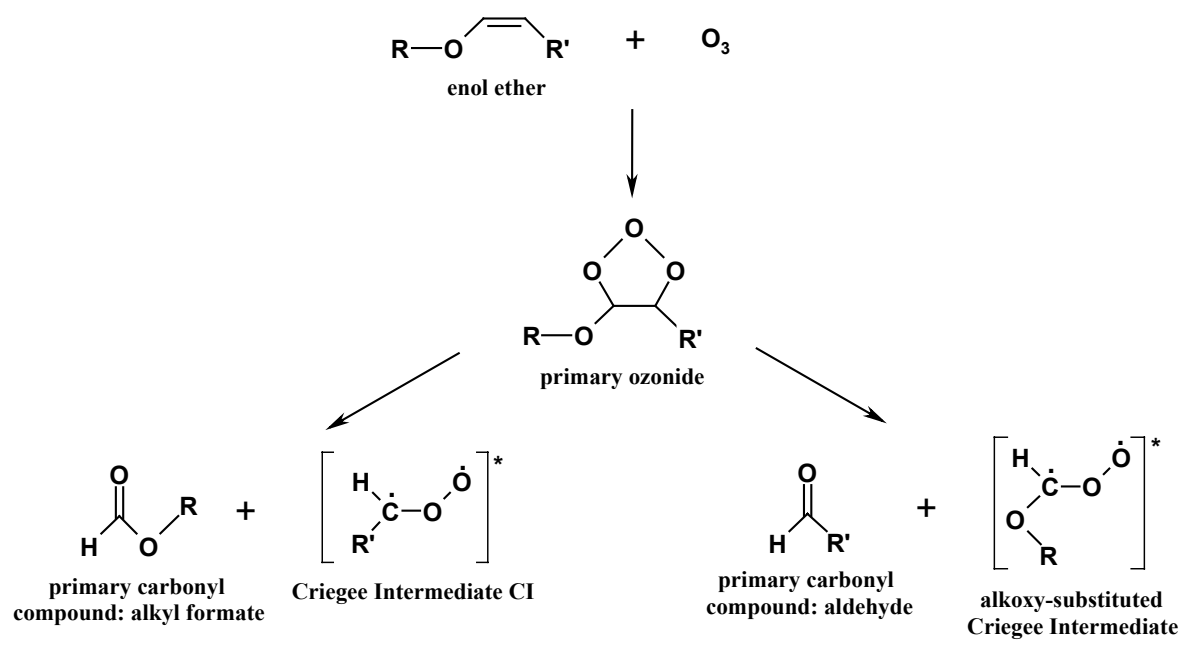

Fig. 1. General mechanism of the ozonolysis of enol ethers.

ozonide into both pathways was deduced to be $(71 \pm 13)$ $\%$ for the "ethyl formate $+\mathrm{C}_{1}$-Cl" channel for EVE, and $(83 \pm 13) \%$ for the "ethyl formate $+\mathrm{C}_{2}$-CI" channel for EPE (Sadezky, 2005). It has to be stressed that the yield of the $\mathrm{C}_{1}$ and $\mathrm{C}_{2}$ SCIs is estimated to be nearly $20-40 \%$ per reacted enol ether (Sadezky, 2005).

The gas-phase chemistry of the ozonolysis of the unsaturated ethers will not be treated in this paper, but will be published elsewhere (Sadezky et al., 2006 ${ }^{1}$ ). An elaborate mechanism of the gas phase ozonolysis of methyl vinyl ether has been presented by Klotz et al. (2004), and their results show the same trend as observed in our studies (Sadezky, 2005).

Besides the classical mechanism of the ozonolysis of unsaturated ethers in the gas phase, as presented above, there exists another mechanism in the liquid phase. Keul et al. (1985) investigated the ozonolysis of different alkyl vinyl ethers in a variety of solvents at $-78^{\circ} \mathrm{C}$, and observed major yields of alkoxy-1,2-dioxolanes, besides the expected alkoxy-1,2,4-trioxolanes. These products arose from the addition of carbonyl oxide $\mathrm{CH}_{2} \mathrm{OO}$, produced upon ozonolysis of vinyl ethers from decomposition of the primary ozonide, to the double bond of the vinyl ethers by 1,3-cycloaddition (Fig. 2).

\subsection{Aerosol formation from gas-phase ozonolysis of AVE}

\subsubsection{Size distribution of SOA particles}

Typical time evolution of the particle number size distribution during experiments of various alkyl vinyl ethers (AVE) is presented in Fig. 3 for ethyl vinyl ether (EVE) (initial mix-

\footnotetext{
${ }^{1}$ Sadezky, A., Winterhalter, R., Mellouki, A., Moortgat, G. K., and Le Bras, G.: Ozonolysis of enol ethers: gas phase products and reaction mechanism, in preparation, 2006.
}

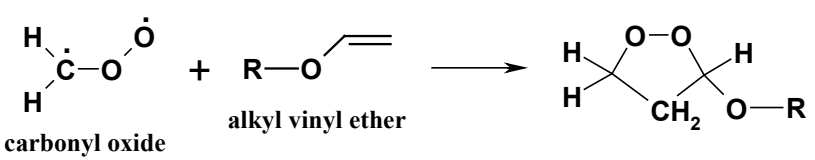

Fig. 2. 1,3-Cycloaddition of the $\mathrm{C}_{1}-\mathrm{CI}$ into the double bond of a vinyl ether.

ing ratios 200 to $400 \mathrm{ppb}$ of reactants $\mathrm{EVE}$ and $\mathrm{O}_{3}$ ). The SOA appears as a single aerosol mode, whose time evolution is sequentially displayed with different colours for different reaction times of the EVE ozonolysis. Formation of detectable particles $(>10 \mathrm{~nm})$ is observed after $3 \mathrm{~min}$, given by the turquoise-coloured size distribution. A maximum total particle concentration of $5 \times 10^{5}$ to $1 \times 10^{6}$ particle $/ \mathrm{cm}^{3}$ is reached after $5 \mathrm{~min}$ at mode diameters (top point of the aerosol mode) around $20 \mathrm{~nm}$ (pink-coloured size distribution). With increasing reaction time, the total particle concentration decreases due to particle coagulation, while the particle diameter increases due to condensation of gaseous reaction products onto the particle surfaces and to coagulation. At the end of the reaction (after $45 \mathrm{~min}$ ), the SOA size distribution is stable at mode diameters around $50 \mathrm{~nm}$ and a total particle concentration of $1 \times 10^{5}$ particle $/ \mathrm{cm}^{3}$. Similar observations were made for the other AVE under similar experimental conditions and initial reactant mixing ratios.

No seed aerosol is used, and detectable particle background concentrations $(>3 \mathrm{~nm})$ are measured to be lower than 200 particle $/ \mathrm{cm}^{3}$.

\subsubsection{SOA yields and partitioning coefficients}

Total aerosol mass concentrations $\left(\mu \mathrm{g} / \mathrm{m}^{3}\right)$ were calculated from the measured number size distributions by assuming spherical particles with a density of $1 \mathrm{~g} / \mathrm{cm}^{3}$. Figure 4 shows 
Table 1. SOA formation during ozonolysis of alkyl vinyl ethers (AVE): SOA mass yields $a$ (Eq. 1) and SOA formation thresholds $\triangle A V E_{\text {thresh }}$ in comparison with the yields $\alpha_{i}$ and partitioning coefficients $K_{i}$ of a hypothetical semi-volatile SOA constituent $i$ (Eq. 4), and estimated saturation vapour pressures $P_{i}^{\circ}$ (Eq. 5) and $P_{\text {vap }}$ (Eq. 6) of main SOA constituents.

\begin{tabular}{lcccccc}
\hline AVE & $a(\%)$ & $\begin{array}{c}\text { SOA formation threshold } \\
\Delta A V E_{\text {thresh }}\end{array}$ & $\begin{array}{c}\alpha_{i} \\
(\%)\end{array}$ & $\begin{array}{c}K_{i} \\
\left(\mathrm{~m}^{3} / \mu \mathrm{g}\right)\end{array}$ & $\begin{array}{c}P_{i}^{\circ} \\
(\mu \text { Torr })\end{array}$ & $\begin{array}{c}P_{\text {vap }} \\
(\mu \text { Torr })\end{array}$ \\
\hline EVE* $^{*}$ & $3.5 \pm 0.2$ & $(173 \pm 6) \mu \mathrm{g} / \mathrm{m}^{3}(58 \pm 2) \mathrm{ppb}$ & $3.5 \pm 0.1$ & $0.17 \pm 0.02$ & 0.27 & 1.48 \\
PVE* $^{*}$ & $3.8 \pm 0.2$ & $(190 \pm 6) \mu \mathrm{g} / \mathrm{m}^{3}(54 \pm 2) \mathrm{ppb}$ & $3.8 \pm 0.2$ & $0.14 \pm 0.02$ & 0.33 & 1.50 \\
BVE* $^{3}$ & $4.3 \pm 0.4$ & $(223 \pm 45) \mu \mathrm{g} / \mathrm{m}^{3}(54 \pm 11) \mathrm{ppb}$ & $4.4 \pm 0.2$ & $0.10 \pm 0.01$ & 0.46 & 1.70 \\
TBVE* $^{3}$ & $1.6 \pm 0.3$ & $(407 \pm 88) \mu \mathrm{g} / \mathrm{m}^{3}(100 \pm 22) \mathrm{ppb}$ & $1.4 \pm 0.2$ & $0.20 \pm 0.06$ & 0.23 & 1.17 \\
IBVE* $^{*}$ & $4.4 \pm 0.1$ & $(151 \pm 19) \mu \mathrm{g} / \mathrm{m}^{3}(37 \pm 5) \mathrm{ppb}$ & $4.7 \pm 0.2$ & $0.13 \pm 0.01$ & 0.36 & 1.19 \\
IBVE*,o $^{*}$ & $0.9 \pm 0.1$ & $(202 \pm 7) \mu \mathrm{g} / \mathrm{m}^{3}(49 \pm 1) \mathrm{ppb}$ & $0.9 \pm 0.1$ & $0.60 \pm 0.08$ & 0.08 & 0.32 \\
MVE $^{\#}$ & $0.66 \pm 0.07$ & $(162 \pm 38) \mu \mathrm{g} / \mathrm{m}^{3} 68 \mathrm{ppb}$ & $0.66 \pm 0.13$ & $0.98 \pm 0.27$ & 0.05 & 0.33 \\
\hline
\end{tabular}

* this work

\# Klotz et al. (2004)

o with an excess of $\mathrm{C}_{6} \mathrm{H}_{12}$

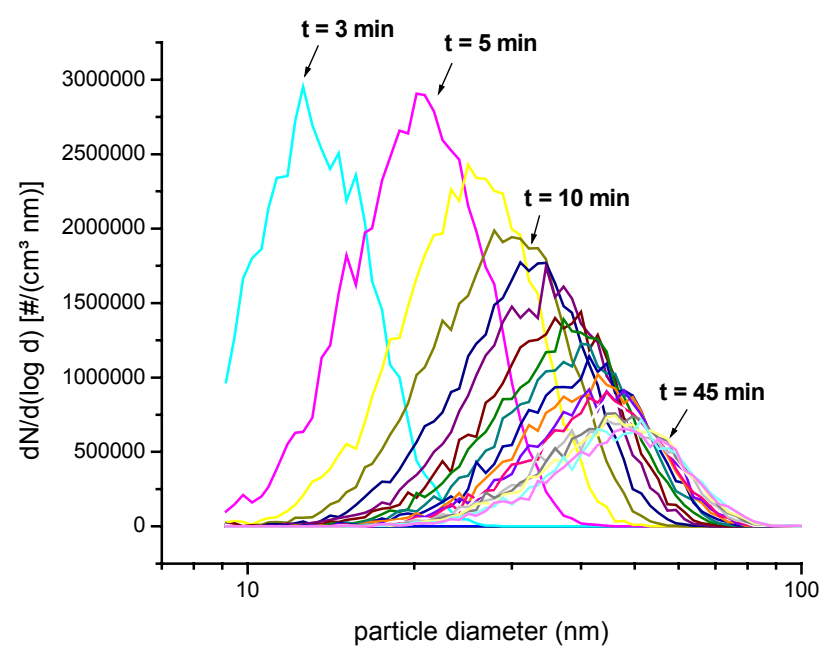

Fig. 3. Evolution of the SOA size distribution with reaction time (t) during ozonolysis of EVE (initial reactant mixing ratios: $300 \mathrm{ppb}$ ).

for propyl vinyl ether (PVE) plots of the total mass concentration $M_{0}$ of aerosol formed as a function of reaction time (Fig. 4a) and of the mass concentration of the ether reacted, $\triangle P V E$ (Fig. 4b). The linear part of the plot in Fig. $4 \mathrm{~b}$ characterizes the SOA formation before a final and stable total SOA mass concentration $M_{0}=18 \mu \mathrm{g} / \mathrm{m}^{3}$ for PVE is reached. These final SOA mass concentrations for the other ethers, which are reached after 15 to $20 \mathrm{~min}$, were: $M_{0}=13 \mu \mathrm{g} / \mathrm{m}^{3}, 25 \mu \mathrm{g} / \mathrm{m}^{3}, 14 \mu \mathrm{g} / \mathrm{m}^{3}$, and $7 \mu \mathrm{g} / \mathrm{m}^{3}$ for ethyl vinyl ether (EVE), $n$-butyl vinyl ether (BVE), iso-butyl vinyl ether (IBVE) and $t$-butyl vinyl ether (TBVE), respectively. It is clearly evident from Fig. $4 \mathrm{~b}$ that a certain quantity of the AVE must have reacted before SOA is formed and observed. The concentration of enol ether reacted until formation of detectable aerosol particles is observed is referred to as threshold quantity $\triangle A V E_{\text {thresh }}$. $\triangle A V E_{\text {thresh }}$ corre- sponds to the intersection of the linear section with the $\mathrm{x}$-axis representing the mass of reacted AVE, $\triangle A V E$. The slope of this linear section (Fig. 4b) gives the aerosol yield, $a$, hereby ignoring the threshold quantity $\triangle A V E_{\text {thresh }}$ reacted before:

$M_{0}=a \times \triangle A V E+b$

with $M_{0}=$ total aerosol mass concentration $\left(\mu \mathrm{g} / \mathrm{m}^{3}\right), \Delta A V E$ $=$ mass of reacted $\operatorname{AVE}\left(\mu \mathrm{g} / \mathrm{m}^{3}\right)$, and $a=$ aerosol yield.

The aerosol profiles can also be evaluated by the adsorption/partitioning model developed by Odum et al. (1996). In this model hypothetical semi-volatile compounds $i$ are partitioned between the gas and aerosol phase, as expressed in the Eq. (2):

$Y_{f}=M_{0} \Sigma \alpha_{i} K_{i} /\left(1+K_{i} M_{0}\right)$

$Y_{f}$ is the fractional SOA yield calculated by

$Y_{f}=M_{0} / \Delta A V E$

The partitioning coefficients $K_{i}$ and the formation yields $\alpha_{i}$ for the semi-volatile compounds $i$ can be obtained from a least-square fit of the observed aerosol yield $Y_{f}$ as a function of the aerosol mass $M_{0}$. Here it is assumed that only one semi-volatile compound $i$ is partitioned for every AVE, leading to Eq. (4):

$Y_{f}=M_{0}\left[\alpha_{i} K_{i} /\left(1+K_{i} M_{0}\right)\right]$

The corresponding plots and least-square fits for the different AVEs are shown in Fig. 5, combining the results of three to four repetitive ozonolysis experiments for each AVE under similar experimental conditions.

Table 1 summarizes the results of both methods for the evaluation of SOA formation profiles in the reaction of the five studied AVE with ozone. The SOA mass yields $a$ are in very good agreement with the formation yields $\alpha_{i}$ of the hypothetical semi-volatile compound $i$. For EVE, PVE, BVE 
and IBVE typical yields range from 3.5 to $4.7 \%$. Threshold quantities $\triangle A V E_{\text {thresh }}$ vary between 37 and $58 \mathrm{ppb}$. For TBVE the aerosol yield is much smaller (1.4 to $1.6 \%$ ) with a significantly higher $\triangle A V E_{\text {thresh }} \approx 100 \mathrm{ppb}$. All values obtained for the AVE in this work are in good agreement with those obtained by Klotz et al. (2004) for methyl vinyl ether MVE using the same methods (Table 1). Moreover, comparison of the ozonolysis experiments of IBVE with and without an excess of cyclohexane $\mathrm{C}_{6} \mathrm{H}_{12}(\mathrm{OH}$ scavenger) shows that the presence of an excess of $\mathrm{C}_{6} \mathrm{H}_{12}$ reduces the SOA yield from $4.4 \%$ to below $1 \%$ in the ozonolysis of IBVE. A similar and systematic decrease of SOA yields in the presence of an excess of cyclohexane has been observed in separate experiments for all five alkyl vinyl ethers studied (Sadezky, 2005).

Saturation vapor pressures of the SOA forming organic compounds can be estimated by two different methods based on the results in Table 1 . The partitioning coefficient $K_{i}$ $\left(\mu \mathrm{g} / \mathrm{m}^{3}\right)$ of the hypothetical semi-volatile compound $i$ is inversely proportional to its saturation vapor pressure $P_{i}^{\circ}$ (Torr) according to the following relationship (Eq. 5) (Odum et al., 1996; Pankow, 1994):

$P_{i}^{\circ}=(760 \mathrm{R} T) /\left(M W_{i} 10^{6} K_{i} \zeta_{i}\right)$

with $\mathrm{R}=8.206 \times 10^{-5}\left(\mathrm{~m}^{3} \mathrm{~atm}\right) /(\mathrm{mol} \mathrm{K})$ and $T=296 \mathrm{~K}$. In the later sections, the newly formed aerosol is shown by $\mathrm{ESI}(+) / \mathrm{MS}$ to consist mainly of oligomers in the mass range 300 to $500 \mathrm{u}$. Assuming that the hypothetical semi-volatile compound $i$ represents an average of these oligomers, and that other unidentified SOA constituents are minor, a mean molar weight $M W_{i}=400 \mathrm{~g} / \mathrm{mol}$ is assumed. With the elemental compositions of the oligomers pointing out to an oligoperoxidic structure (see later sections), the compound $i$ is assumed to be moderately polar, giving an activity coefficient $\zeta_{i} \approx 1$. Another method to estimate the mean saturation vapor pressures $P_{\text {vap }}$ [ $\mu$ Torr] of the main SOA constituents relies on the measured yields of these constituents, here assumed to be nearly equal to the measured SOA yields $a$, and the SOA formation thresholds $\Delta A V E_{\text {thresh }}$ [ppb] (Eq. 6) (Koch et al., 2000):

$P_{\text {vap }}=a \times \Delta A V E_{\text {thresh }} \times 10^{-9} \times P_{\text {total }} \times 10^{6}$

with $P_{\text {total }}=730$ Torr. Both methods give saturation vapor pressures between 0.1 and $1.8 \mu$ Torr, thus within one order of magnitude.

These values can only be considered as an estimate. Both calculations are based on liquid compounds with flat surfaces and do not take into account the effects of Kelvin's law, which are expected to be significant for the observed particle sizes of several nanometers. The real saturation vapor pressures of the SOA forming compounds might thus be much lower, the range of values given by the two above-described calculation methods representing upper limits.
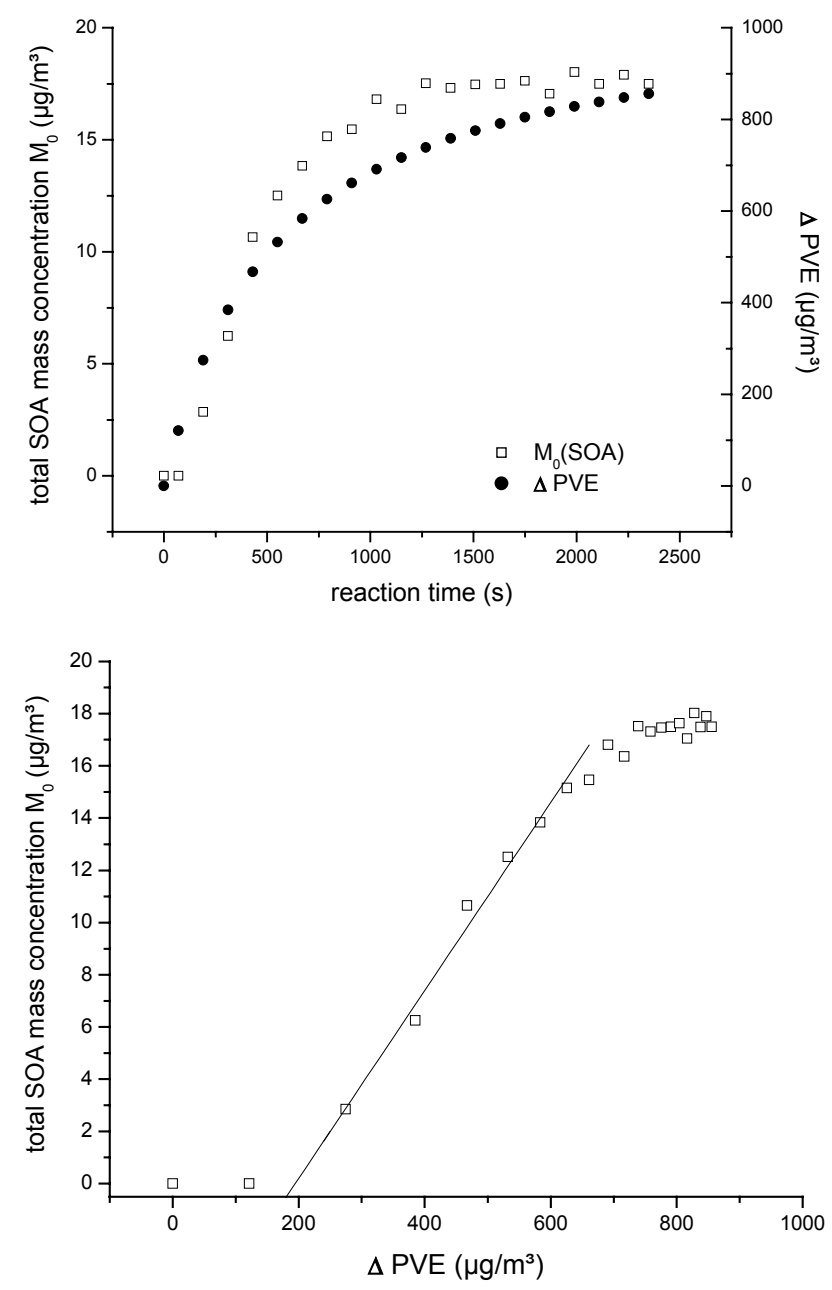

Fig. 4. Ozonolysis of PVE (initial reactant mixing ratios: $300 \mathrm{ppb}$ ): (a) total aerosol mass concentration formed and reacted PVE versus reaction time (b) total aerosol mass concentration formed versus reacted $P V E$.

3.3 Chemical analysis of the SOA composition and formation of oligomers

\subsubsection{Observation of oligomers by ESI(+)/MS-TOF}

Deploying the smooth ionisation of the electrospray technique, oligomeric products were detected in the SOA filter samples for all the enol ethers studied. Figures A1a-d (see supplemental material, http://www.atmos-chem-phys.net/ 6/5009/2006/acp-6-5009-2006-supplement.pdf) show the mass spectra of the aerosol samples obtained during the ozonolysis of EVE, EPE, PVE and TBVE. The spectra show the presence of ions in the range between $\mathrm{m} / \mathrm{z} 200$ and 800 with regular differences $\Delta m / z$. The pseudomolecular ions are positively charged of the type $[\mathrm{M}+\mathrm{H}]^{+}$, where $\mathrm{M}$ is the mass of the molecular species. 
Table 2. Oligomer pseudomolecular ion series detected by ESI(+)/MS-TOF in the SOA formed during ozonolysis of enol ethers (n: minimum number of chain units determined by MS/MS experiments) (MW: molar weight $[\mathrm{g} / \mathrm{mol}])$.

\begin{tabular}{|c|c|c|c|c|c|c|c|c|c|c|c|}
\hline \multirow{2}{*}{$\begin{array}{l}\text { Ether } \\
\text { n }\end{array}$} & \multicolumn{11}{|c|}{ Ion Series (m/z) } \\
\hline & $n=1$ & $n=2$ & $n=3$ & $n=4$ & $n=5$ & $n=6$ & $n=7$ & $n=8$ & $n=9$ & $n=10$ & \\
\hline Ethyl Propenyl Ether & & 339 & 399 & 459 & 519 & 579 & 639 & 699 & 759 & & (a) \\
\hline (MW 86 g/mol) & & & 357 & 417 & 477 & & & & & & (B) \\
\hline \multirow[t]{3}{*}{$\mathrm{EPE}, \mathrm{C}_{2} \mathrm{H}_{5} \mathrm{OCH}=\mathrm{CHCH}_{3}$} & 265 & 325 & 385 & 445 & & & & & & & (C) \\
\hline & 293 & 353 & 413 & 473 & 533 & & & & & & (D) \\
\hline & & & & 489 & 549 & 609 & 669 & 729 & 789 & & (E) \\
\hline Ethyl Vinyl Ether & & 283 & 329 & 375 & 421 & 467 & 513 & & & & (a) \\
\hline (MW 72g/mol) & & & 345 & 391 & 437 & 483 & & & & & (b) \\
\hline \multicolumn{12}{|l|}{ EVE, $\mathrm{C}_{2} \mathrm{H}_{5} \mathrm{OCH}=\mathrm{CH}_{2}$} \\
\hline Propyl Vinyl Ether & & 297 & 343 & 389 & 435 & 481 & 527 & 573 & & & (a) \\
\hline (MW $86 \mathrm{~g} / \mathrm{mol}$ ) & & & 359 & 405 & 451 & 497 & & & & & (b) \\
\hline \multicolumn{12}{|l|}{ PVE, $\mathrm{C}_{3} \mathrm{H}_{7} \mathrm{OCH}=\mathrm{CH}_{2}$} \\
\hline n-Butyl Vinyl Ether & & & 357 & 403 & 449 & 495 & 541 & 587 & 633 & 679 & (a) \\
\hline (MW $100 \mathrm{~g} / \mathrm{mol}$ ) & & & & & 465 & 511 & 557 & 603 & 649 & 695 & (b) \\
\hline \multirow[t]{2}{*}{ BVE, $\mathrm{C}_{4} \mathrm{H}_{7} \mathrm{OCH}=\mathrm{CH}_{2}$} & 295 & 341 & 387 & 433 & 479 & 525 & 571 & 617 & 663 & & (c) \\
\hline & & 293 & 339 & 385 & 431 & 477 & 523 & & & & (d) \\
\hline iso-Butyl Vinyl Ether & & 311 & 357 & 403 & 449 & 495 & 541 & 587 & 633 & & (a) \\
\hline (MW $100 \mathrm{~g} / \mathrm{mol})$ & & & 373 & 419 & 465 & 511 & 567 & 603 & & & (b) \\
\hline IBVE, & & 341 & 387 & 433 & 479 & 525 & 571 & & & & (c) \\
\hline$\left(\mathrm{CH}_{3}\right)_{2} \mathrm{CHCH}_{2} \mathrm{OCH}=\mathrm{CH}_{2}$ & 247 & 293 & 339 & 385 & 431 & & & & & & (d) \\
\hline t-Butyl Vinyl Ether (MW 100 & 265 & 311 & 357 & 403 & 449 & 495 & 541 & & & & (a) \\
\hline $\mathrm{g} / \mathrm{mol})$ & 295 & 341 & 387 & 433 & 479 & & & & & & (c) \\
\hline TBVE, & 247 & 293 & 339 & 385 & & & & & & & (d) \\
\hline$\left(\mathrm{CH}_{3}\right)_{3} \mathrm{COCH}=\mathrm{CH}_{2}$ & & & & & 427 & 473 & 519 & 565 & 611 & & (e) \\
\hline
\end{tabular}

Detailed analysis of the ion spectra revealed that the ion peaks could be grouped in series, whose ions display regular differences of $\Delta m / z=46$ for all the investigated alkyl vinyl ethers AVE $\left(\mathrm{ROCH}=\mathrm{CH}_{2}\right)$, and $\Delta m / z=60$ for the ethyl propenyl ether EPE $\left(\mathrm{C}_{2} \mathrm{H}_{5} \mathrm{OCH}=\mathrm{CHCH}_{3}\right)$. Such a regular structure is typical for oligomers, consisting of a chain unit with mass 46 and 60 , respectively.

The different ion series for the various unsaturated ethers are presented in Table 2 and correspond to different types of oligomers designated (a), (b), (c), (d), (e) for the AVE and (a), (B), (C), (D), (E) for EPE. In order to better distinguish the series, the peaks of the series are identified by different colours, corresponding to the colours of the peaks of Fig. A1a-d. The most intense series observed for each ether is coloured in red, and is assigned as oligomer of type (a). As described in a later section of this publication, ESI(+)/MS/MS-TOF experiments allowed to fragment the pseudomolecular ions $[\mathrm{M}+\mathrm{H}]^{+}$and thus to determine the minimum number $n$ of chain units 46 or 60 contained in the molecular species. In Figs. A1a-d, $n$ are given for the pseudomolecular ions $[\mathrm{M}+\mathrm{H}]^{+}$of the most intensive oligomer series designated as type (a). Ions of type (a) and ions of weaker oligomer series suggested to carry similar numbers of chain units, are arranged in vertical columns in Table 2.

Some interesting relationships between the oligomer ions shown in Table 2 and Figs. A1a-d and the original structure of the enol ethers can be derived. The schematic structure of an enol ether is shown in Fig. 6 and displays the two alkyl substituents, $\mathrm{R}^{\prime}$ on the vinylic side $=\mathrm{CHR}^{\prime}$ of the double bond and $\mathrm{R}$ on its enolic side $=\mathrm{CHOR}$

The substituents $\mathrm{R}$ and $\mathrm{R}^{\prime}$ vary among the different ethers studied in this work. $\mathrm{R}^{\prime}=\mathrm{H}$ for the five alkyl vinyl ethers (AVE, $\mathrm{ROCH}=\mathrm{CH}_{2}$ ), while $\mathrm{R}^{\prime}=\mathrm{CH}_{3}$ for ethyl propenyl ether (EPE, $\mathrm{C}_{2} \mathrm{H}_{5} \mathrm{OCH}=\mathrm{CHCH}_{3}$ ). $\mathrm{R}^{\prime}$ differs thus by mass 14 $\left(\mathrm{CH}_{2}\right)$ between the AVE and EPE, a difference that is reflected in the masses of the observed oligomer chain units, which are of $\Delta m / z=46$ for the AVE and of $\Delta m / z=60=46+14$ for EPE. This indicates that the oligomer chain unit might depend on the alkyl substituents on the vinylic side $=\mathrm{CHR}^{\prime}$ of the double bond. A comparison of the oligomers of type (a) formed from the five AVE $\left(\mathrm{ROCH}=\mathrm{CH}_{2}\right)$ shows that their masses differ by as many multiples of mass 14 $\left(\mathrm{CH}_{2}\right)$ as do the original alkyl vinyl ethers among each other. As can be seen in Table 2 the oligomers formed 

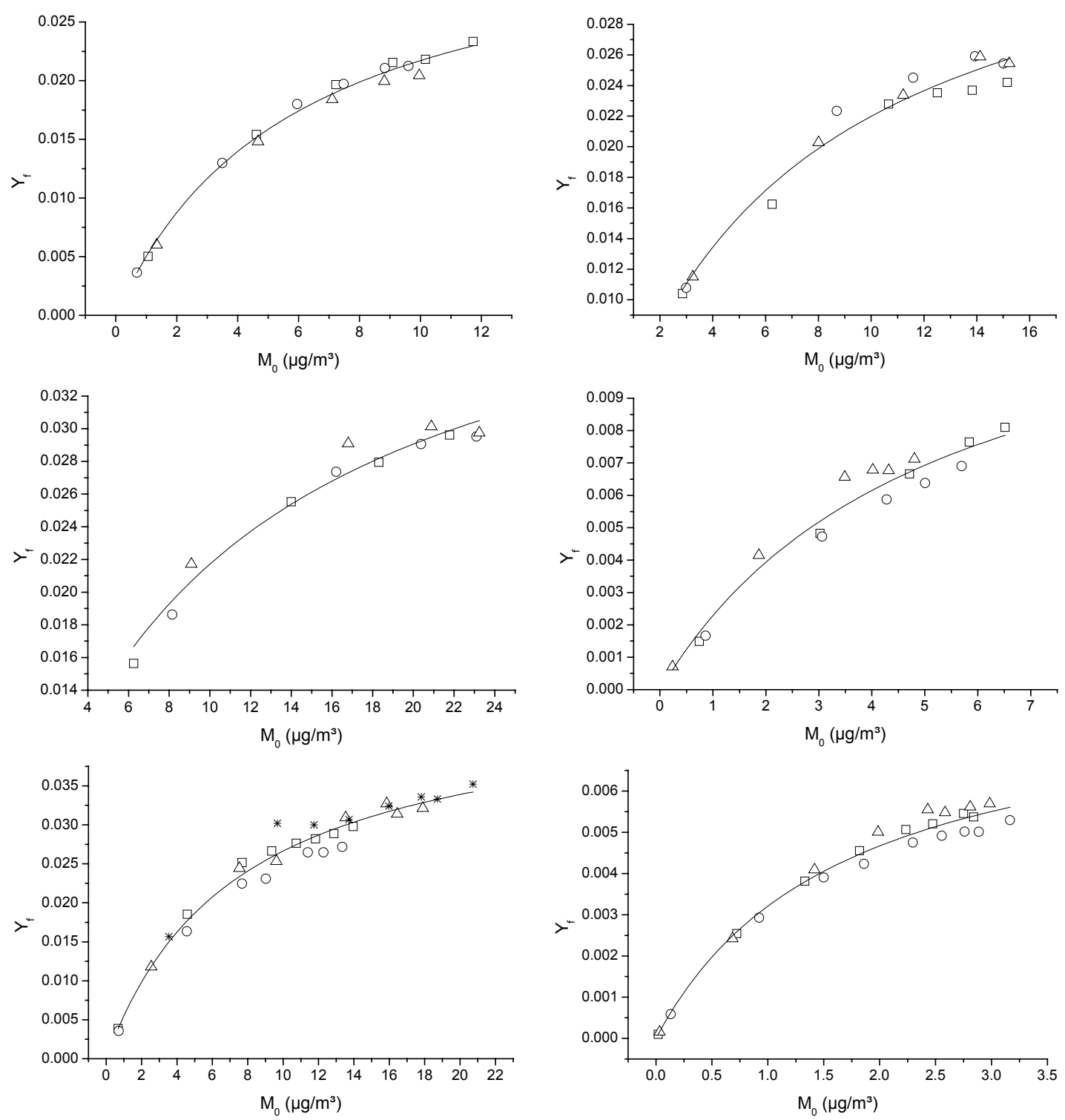

Fig. 5. SOA yield $Y_{f}$ as a function of the aerosol mass $M_{0}$ during the ozonolysis of alkyl vinyl ethers (initial reactant mixing ratios: $300 \mathrm{ppb}$ ). Symbols $(\square, \bigcirc, \Delta, *)$ designate measurements from different experiments under similar experimental conditions. (a) Ethyl vinyl ether (b) Propyl vinyl ether (c) $n$-Butyl vinyl ether (d) $t$-Butyl vinyl ether (e) $i$ so-Butyl vinyl ether (f) $i$ so-Butyl vinyl ether with an excess of cyclohexane.

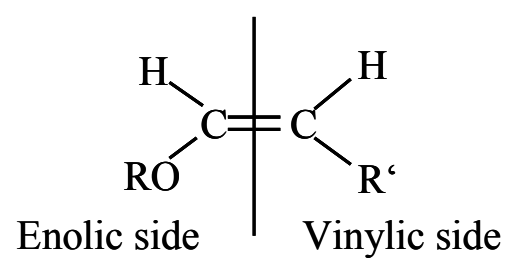

Fig. 6. Schematic structure of an enol ether. from the three isomers of butyl vinyl ether, BVE, IBVE and TBVE, show the same ions of type (a). Moreover, the type (a) ions are shifted by $\Delta m / z=14$ from EVE to PVE as well as from PVE to the butyl vinyl ethers. Regarding the structure of the original ethers, these shifts might be attributed to the alkyl substituents $\mathrm{R}$ on the enolic side $=\mathrm{CHOR}$ of the double bond, which contain an additional $\mathrm{CH}_{2}$ group between EVE $\left(\mathrm{C}_{2} \mathrm{H}_{5} \mathrm{OCH}=\mathrm{CH}_{2}, \mathrm{R}=\mathrm{C}_{2} \mathrm{H}_{5}\right)$ and PVE $\left(\mathrm{C}_{3} \mathrm{H}_{7} \mathrm{OCH}=\mathrm{CH}_{2}, \mathrm{R}=\mathrm{C}_{3} \mathrm{H}_{7}\right)$, as well as between PVE and the BVEs $\left(\mathrm{C}_{4} \mathrm{H}_{9} \mathrm{OCH}=\mathrm{CH}_{2}, \mathrm{R}=\mathrm{C}_{4} \mathrm{H}_{9}\right)$. Consequently, the alkoxy group OR of the original ether is suggested to be contained once in each oligomer ion. 

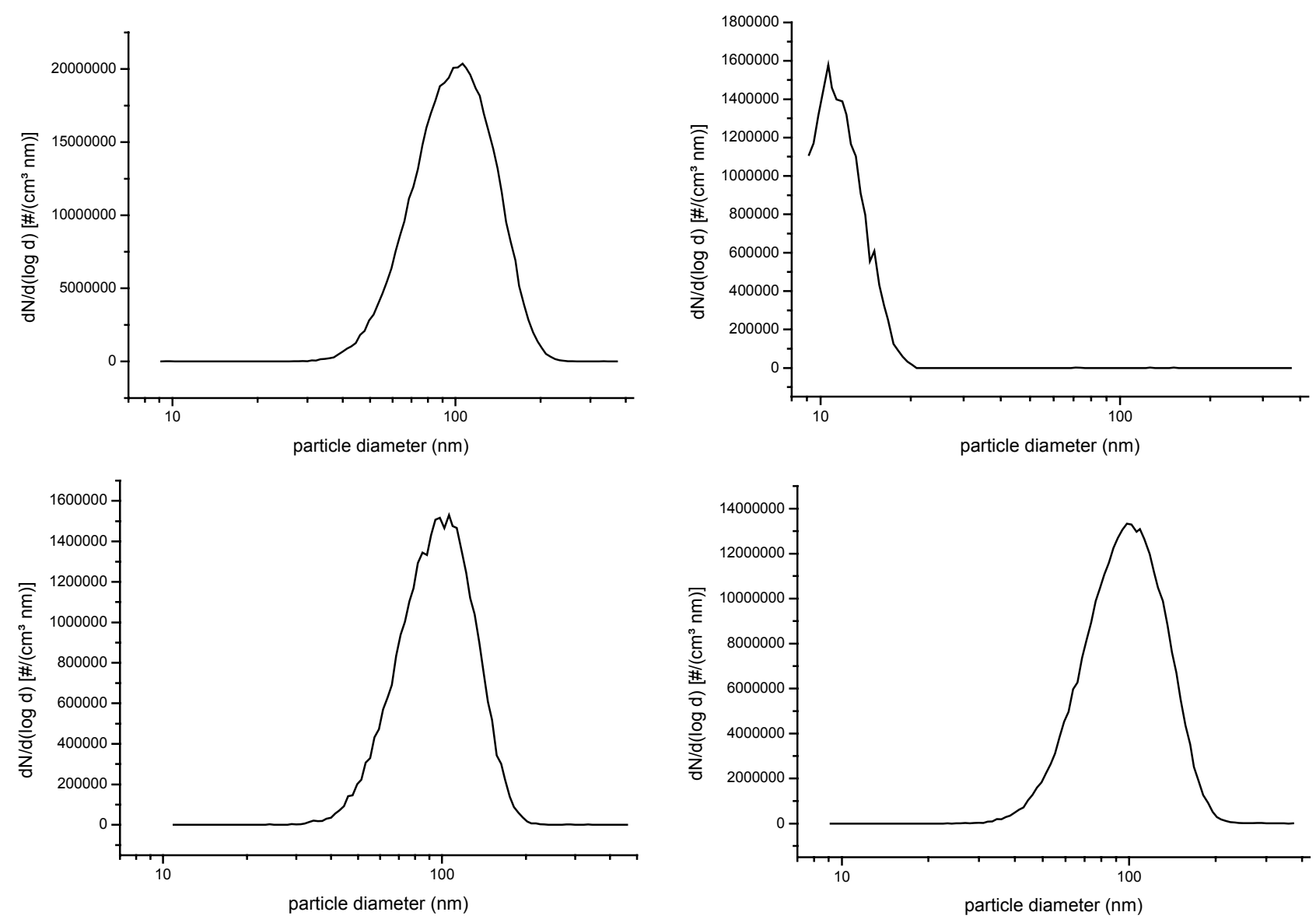

Fig. 7. SOA particle size distributions measured after completion of the reaction, just before the beginning of the filter sampling for chemical analysis by $\operatorname{ESI}(+) / \mathrm{MS}$. (a) $\operatorname{EVE}(9 \mathrm{ppm})+\mathrm{O}_{3}(8 \mathrm{ppm})\left(M_{0}: 5 \mathrm{mg} / \mathrm{m}^{3}\right)\left(\right.$ b) $\mathrm{EVE}(9 \mathrm{ppm})+\mathrm{O}_{3}(8 \mathrm{ppm})+\mathrm{HCOOH}(20 \mathrm{ppm})\left(M_{0}<1 \mu \mathrm{g} / \mathrm{m}^{3}\right)(\mathbf{c})$ $\operatorname{EVE}(9 \mathrm{ppm})+\mathrm{O}_{3}(8 \mathrm{ppm})+$ cyclohexane $(300 \mathrm{ppm})\left(M_{0}: 800 \mu \mathrm{g} / \mathrm{m}^{3}\right)$ (d) $\mathrm{EPE}(9 \mathrm{ppm})+\mathrm{O}_{3}(8 \mathrm{ppm})\left(M_{0}: 3 \mathrm{mg} / \mathrm{m}^{3}\right)$.

Similar observations are made for the other, less intense oligomer series shown in Table 2 and in Figs. A1a-d. Like the oligomer ions of type (a), all weaker series also show chain units of mass 46 for AVE and of mass 60 for EPE. For all AVE except of TBVE, oligomer ions of type (b) are visible, coloured in green in Table 2 and Figs. A1a-d. They differ from the series of type (a) ions by an additional $\Delta m / z=16$, possibly corresponding to an oxygen atom. Consequently, like the type (a) ions, oligomer series of type (b) are also shifted by $\Delta m / z=14$ between EVE and PVE as well as between PVE and BVE/IBVE. The three butyl isomers show a variety of additional ions series labelled (c), (d) and (e). For example, the ion series of type (c) systematically possess an additional $\Delta m / z=14$ with respect to the type (b) oligomer series, and consequently an additional $\Delta m / z=30$ with respect to the type (a) series, eventually accounting in total for a formaldehyde-like unit $\left(\mathrm{CH}_{2} \mathrm{O}\right)$.

The mass spectra obtained from the ozonolysis of ethyl propenyl ether (EPE) also show besides the type (a) oligomer, a variety of additional oligomer series labelled type
(B) through (E). The capital letters distinguish these ion series from those formed from the AVE and designated (b) through (e), as they do not seem to show any analogy.

\subsubsection{Additional test experiments}

Background experiments were performed to assure that the detected oligomers are definitely produced through the ozonolysis of unsaturated ethers during the typical duration of the experiment $(45 \mathrm{~min})$ and substantially contribute to SOA formation. No aerosol was formed when $9 \mathrm{ppm}$ of EVE was introduced alone in the reactor, nor when solely ozone (8 ppm) was introduced, and filter samples of both experiments did not show any of the described oligomer ions (Fig. A2).

SOA formation was observed to be strongly reduced or suppressed upon addition of $\mathrm{HCOOH}$ in excess during gasphase ozonolysis of enol ethers (Sadezky, 2005) and terpenes (Bonn et al., 2002). The addition of $20 \mathrm{ppm}$ of $\mathrm{HCOOH}$ to the mixture of EVE ( $9 \mathrm{ppm})$ and $\mathrm{O}_{3}(8 \mathrm{ppm})$ reduced the aerosol yield to less than $1 \mu \mathrm{g} / \mathrm{m}^{3}$, whereas in the 
absence of $\mathrm{HCOOH}$ the typical aerosol yield was in the order of $5 \mathrm{mg} / \mathrm{m}^{3}$. SOA particle size distributions measured after completion of the reaction, just before the beginning of the filter sampling, are shown for both experiments in Figs. 7a and $b$. The mass spectrum of the collected filter samples of the experiment with added $\mathrm{HCOOH}$ is displayed in Fig. A2b and does not show any characteristic ions of the oligomers described before. The most intense ions visible in the Figs. A2a and b, 288 and 299, were proven by MS/MS experiments not to possess an oligomeric structure. $\mathrm{HCOOH}$ is known to scavenge Criegee Intermediates formed during alkene ozonolysis, leading to the formation of gaseous hydroperoxy formates (e.g. Klotz et al., 2004; Neeb et al., 1998; Horie et al., 1997; Sadezky, 2005). Considering that this reaction is responsible for the observed strong reduction of SOA formation, the scavenging effect of $\mathrm{HCOOH}$ indicates that Criegee Intermediates play a decisive role in SOA formation. The addition of $\mathrm{H}_{2} \mathrm{O}$ to the ozonolysis system also caused a remarkable reduction of SOA formation (Sadezky, 2005).

In the presence of $300 \mathrm{ppm}$ of cyclohexane (an OH scavenger), the total aerosol yield decreases by $80 \%$, as is also described for IBVE in the previous section (Table 1). However, mass spectra obtained from filter samples of these experiments remained unchanged in comparison with those from ozonolysis experiments with mixtures of ether and ozone only, showing the same oligomer ions. The SOA particle size distribution measured after completion of the reaction, before the beginning of the filter sampling, is shown in Fig. 7c for an ozonolysis experiment of EVE (9 ppm of EVE and 8 ppm of ozone) with added $300 \mathrm{ppm}$ of cyclohexane producing about $0.8 \mathrm{mg} / \mathrm{m}^{3}$ of SOA. For comparison, also the SOA particle size distribution measured for the reaction of a mixture of EPE ( $9 \mathrm{ppm})$ with ozone ( $8 \mathrm{ppm})$, leading to the formation of about $3 \mathrm{mg} / \mathrm{m}^{3}$ of SOA, is shown in Fig. $7 \mathrm{~d}$.

\subsubsection{Separation of the oligomers by HPLC}

The different oligomeric constituents of the SOA may be separated by HPLC according to their number of chain units. An example of the TIC (total ion current) chromatogram is shown in Fig. A3a, representing the SOA formed during ozonolysis of EVE, where chromatographic peaks in different retention time (RT) zones surrounded with different colours are marked. In Fig. A3b, the mass spectra of each of these four retention time (RT) zones, displayed in the corresponding colours, are overlaid. Figure A3b shows that the most intense ion present in each retention time (RT) zone represents a pseudomolecular ion of the oligomer of type (a) (see Table 2 and Fig. A1a), with $m / z=329$ for the first (blue-marked) retention time zone at RT $=16 \mathrm{~min}, m / z=375$ for the second (red-marked) at RT=17 min, $m / z=421$ for the third (green-marked) at RT=17.9 min, and $m / z=467$ for the fourth (violet-marked) at RT=18.5 min. The less intense pseudomolecular ions of the oligomer of type (b) with $m / z=345$ (blue-marked zone, $\mathrm{RT}=16 \mathrm{~min}$ ), 391 (red-marked zone, RT=17 min), 437 (green-marked zone, RT=17.9 min) and 483 (violet-marked zone, $\mathrm{RT}=18.5 \mathrm{~min}$ ) are also shown (see Table 2 and Fig. A1a). Thus, with increasing retention time, from one chromatographic peak to the next, the masses of the detected oligomeric pseudomolecular ions increase by $\Delta m / z=46$, that is, by the mass of a chain unit. Similar TIC chromatograms and corresponding mass spectra were obtained for the SOA formed from ozonolysis of the other AVEs, where the oligomers all differ with the chain unit $\Delta m / z=46$ between two consecutive chromatographic peaks, and for EPE, where the chain unit is $\Delta m / z=60$. For all enol ethers, retention times of the different oligomers strictly increase with increasing number of chain units. A straight increase or decrease of the retention time with the number of chain units is a characteristic behaviour of polymeric compounds with oxygenated chain carriers, such as ethylene oxide, in reverse-phase liquid chromatography (Chaimbault et al., 1998).

The peaks at retention times (RT) near 16 and $17 \mathrm{~min}$ (blue-marked and red-marked zones) of the TIC chromatogram of Fig. A3a can be resolved in the XIC (eXtracted Ion Current) mode as shown in Fig. A3c. The blue traces correspond to $m / z=329$ and 375 , respectively of the oligomer of type (a), whereas the red traces correspond to $m / z=345$ and 391, of the oligomer of type (b). Four peaks are visible for each ion, which indicates that at least four isomers of the types (a) and (b) exist. Similar observations were made for the ions with $m / z=343$ and 389 (type a) and $m / z=359$ and 405 (type b) for PVE, and for the ions with $m / z=375$ and 403 (type a) and $m / z=373$ and 419 (type b) for $n$-BVE.

\subsubsection{Fragmentation of oligomers using ESI(+)/MS-MS- TOF}

The fragmentation of the pseudomolecular ions using the MS/MS mode confirm that they consist of an oligomeric structure with the chain unit of $\Delta m / z=60$ for SOA formed in the ozonolysis of ethyl propenyl ether (EPE) and $\Delta m / z=46$ for SOA formed from all the alkyl vinyl ethers (AVE) studied. The majority of the observed fragment ions can be classified as being part of fragmentation pathways, formed by successive loss of the chain unit as neutral mass 60 or 46 for EPE and AVE, respectively. Tables $3 \mathrm{a}$ and $\mathrm{b}$ summarize the observed ions of the fragmentation pathways for the oligomers of type (a), respectively involving loss of chain units $\Delta m / z=46$ for AVE (Table 3a), and loss of chain units $\Delta m / z=60$ for EPE (Table 3b). A variety of nine fragmentation pathways can thus be distinguished for an oligomer of type (a).

Generally, for the different AVE, detailed analysis of the MS/MS spectra has lead to the observation that the fragmentation of their oligomers proceeds according to a common scheme. There exist two distinct fragmentation patterns involving the loss of the chain element $\Delta m / z=46$. One 


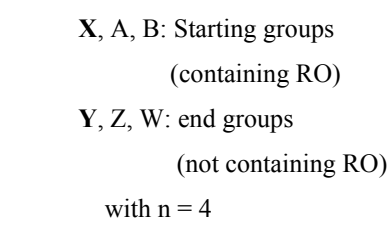

Fragmentation pattern not conserving the RO group in the fragment ions

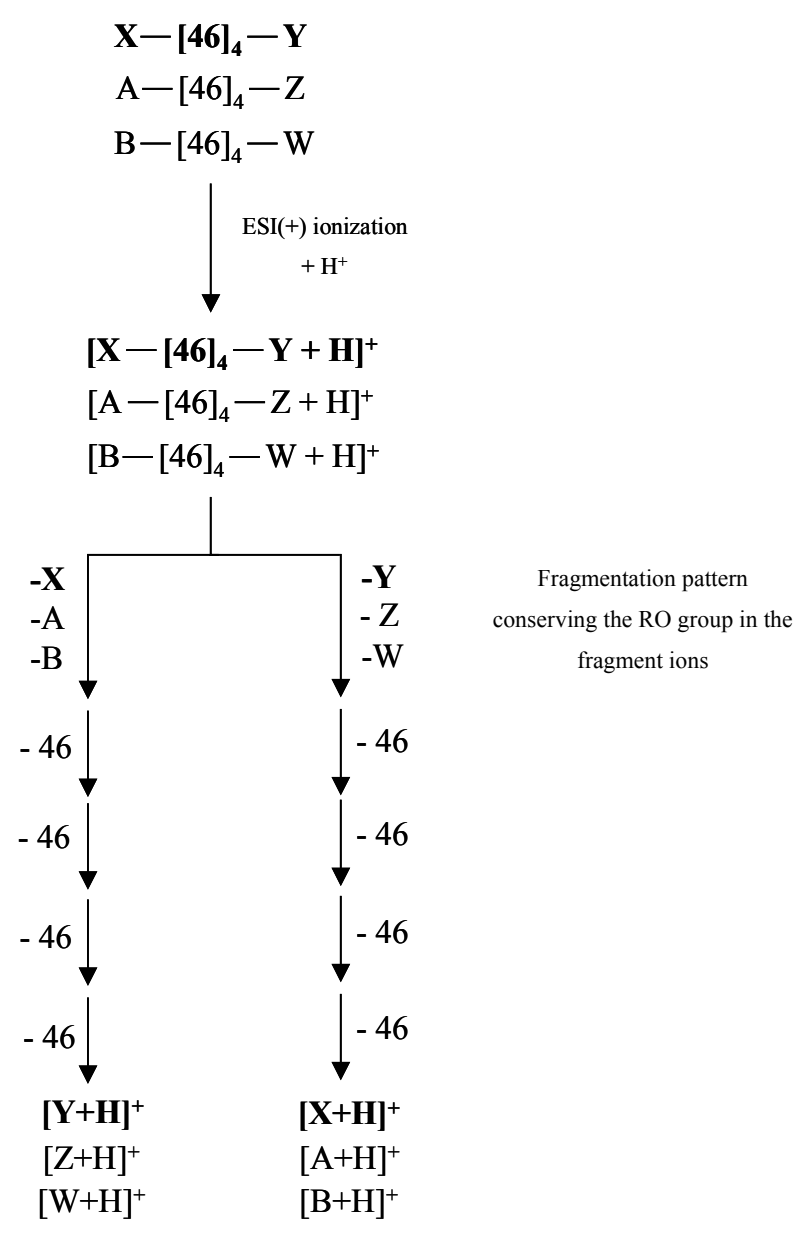

Fig. 8. SOA formed during ozonolysis of alkyl vinyl ethers AVE: Schematic diagram of the linear structure of the oligomers of type (a) and their MS/MS fragmentation involving the successive loss of the chain units of mass 46.

produces series of fragmentations in a way that the RO group clearly remains in the fragment ions. These fragment ions, given in the central column of Table 3a, differ by $\Delta m / z=14$ between EVE and PVE, as well as between PVE and the three BVEs, as do the pseudomolecular ions themselves. The most intense fragmentation pathway showing this pattern is marked in violet colour, and consists a.o. of the ions with $m / z 127,173,219,265$, etc. for EVE (molar weight MW: $72 \mathrm{~g} / \mathrm{mol}$ ), the ions with $\mathrm{m} / z 141,187,233,279$, etc. for PVE (MW: $86 \mathrm{~g} / \mathrm{mol}$ ), and the ions with $m / z 155,201,247,293$, etc. for the three BVE-isomers (MW: $100 \mathrm{~g} / \mathrm{mol}$ ). The other fragmentation pattern produces fragment ions, which do not contain the RO group and thus are identical for all the AVE. Those fragment ions are listed in the right-hand column of Table 3a. The two most important pathways showing this pattern are represented by red and green colours, and consist a.o. of the ions with $m / z 85,131,177,223$, etc. and 99, 145, 191, 237, etc., respectively.

Examples of the MS/MS spectra are displayed in Figs. A4a-d for various unsaturated ethers, which show the fragmentation of a selected specific pseudo-molecular ion of the type (a) oligomer. The three fragmentation pathways highlighted in violet, red and green colours in Table 3a and $\mathrm{b}$ are shown in the MS/MS spectra in Figs. A4a-d and are also schematically displayed in the bottom section of these figures by use of the same colours. The elemental compositions given for the ions and neutral molecules are discussed below. Note that for AVE and EPE, the fragmentation pathways marked in red and green terminate by fragment ions of similar $m / z, 85$ and 99, respectively, and that for EVE and EPE, the fragmentation pathways marked in violet both terminate with fragment ions of a similar $m / z, 127$.

\subsubsection{Principal structure of the oligomer (a)}

The fragmentation pathways characterized by the regular loss of the chain unit with $\Delta m / z=60$ for EPE and $\Delta m / z=46$ for the AVE typically range from $m / z=300$ to 400 , the masses of the pseudo-molecular ions, down to $m / z$ about 100 for the smallest fragment ions (Tables $3 a$ and $b$ ). Thus, they 
Table 3. (a) Ions of fragmentation pathways consisting of successive loss of chain unit $\Delta m / z 46$, with or without conservation of the ether group RO, which were observed for the oligomer of type (a) formed in the ozonolysis of alkyl vinyl ethers (AVE) (MW: molar weight $[\mathrm{g} / \mathrm{mol}])$.

\begin{tabular}{|c|c|c|}
\hline $\begin{array}{c}\text { Ether } \\
\text { Parent Ions }(\mathrm{m} / \mathrm{z})\end{array}$ & $\begin{array}{l}\text { Fragment lon series }(\mathrm{m} / \mathrm{z}) \\
\text { conserving } \mathrm{RO}\end{array}$ & $\begin{array}{c}\text { Fragent lon series }(\mathrm{m} / \mathrm{z}) \\
\text { not-conserving } \mathrm{RO}\end{array}$ \\
\hline Ethyl Vinyl Ether (MW 72 g/mol) & $403,357,311,265,219,173,127$ & \\
\hline$\left(\mathrm{EVE}, \mathrm{C}_{2} \mathrm{H}_{5} \mathrm{OCH}=\mathrm{CH}_{2}\right)$ & $339,293,247,201,155$ & \\
\hline $329,375,421,467$ & $374,328,282,236,190$ & \\
\hline Propyl Vinyl Ether (MW 86 g/mol) & $417,371,325,279,233,187,141$ & \\
\hline$\left(\mathrm{PVE}, \mathrm{C}_{3} \mathrm{H}_{7} \mathrm{OCH}=\mathrm{CH}_{2}\right)$ & $353,307,261,215,169$ & $253,207,161,115$ \\
\hline \multirow[t]{2}{*}{$343,389,435,481$} & $388,342,296,250,204$ & $313,267,221,175,129,83$ \\
\hline & & $315,269,223,177,131,85$ \\
\hline n-Butyl Vinyl Ether (MW $100 \mathrm{~g} / \mathrm{mol}$ ) & & $225,179,133$ \\
\hline$\left(\mathrm{BVE}, \mathrm{C}_{4} \mathrm{H}_{7} \mathrm{OCH}=\mathrm{CH}_{2}\right)$ & & $329,283,237,191,145,99$ \\
\hline $357,403,449,495$ & & $286,240,194,148,102$ \\
\hline iso-Butyl Vinyl Ether (MW $100 \mathrm{~g} / \mathrm{mol}$ ) & $431,385,339,293,247,201,155$ & \\
\hline$\left(\right.$ IBVE, $\left.\left(\mathrm{CH}_{3}\right)_{2} \mathrm{CHCH}_{2} \mathrm{OCH}=\mathrm{CH}_{2}\right)$ & $367,321,275,229,183$ & \\
\hline $357,403,449,495$ & $402,356,310,264,218$ & \\
\hline \multicolumn{3}{|l|}{ t-Butyl Vinyl Ether (MW $100 \mathrm{~g} / \mathrm{mol}$ ) } \\
\hline \multicolumn{3}{|l|}{$\left(\right.$ TBVE, $\left.\left(\mathrm{CH}_{3}\right)_{3} \mathrm{COCH}=\mathrm{CH}_{2}\right)$} \\
\hline $357,403,449,495$ & & \\
\hline
\end{tabular}

Table 3. (b) Ions of fragmentation pathways consisting of sucessive loss of chain unit $\Delta m / z 60$, which were observed for the oligomer of type (a) formed in the ozonolysis of ethyl propenyl ether EPE (MW: molar weight $[\mathrm{g} / \mathrm{mol}]$ ).

\begin{tabular}{|c|c|}
\hline \multicolumn{2}{|l|}{ Parent lons (m/z) } \\
\hline & $367,307,247,187,127$ \\
\hline & $325,265,205,145,85$ \\
\hline & $339,279,219,159,99$ \\
\hline Ethyl Propenyl Ether (MW $86 \mathrm{~g} / \mathrm{mol}$ ) & $381,321,261,201,141$ \\
\hline$\left(\mathrm{EPE}, \mathrm{C}_{2} \mathrm{H}_{5} \mathrm{OCH}=\mathrm{CHCH}_{3}\right)$ & $293,233,173$ \\
\hline \multirow[t]{4}{*}{$279,339,399,459$} & $341,281,221,161$ \\
\hline & $249,189,129$ \\
\hline & $297,237,177,117$ \\
\hline & $296,236,176$ \\
\hline
\end{tabular}

reveal a linear oligomeric structure, which can schematically be represented for an oligomer of type (a) by a chain having a starting group " $\mathrm{X}$ " and an end group " $\mathrm{Y}$ " linked by several chain units of mass 60 or 46 for EPE and AVE, respectively. This structure is schematically pictured in Fig. 8 for an oligomer of type (a) formed from AVE, with chain units of mass 46. The fragmentation initiates with a loss of a neutral species $\mathrm{X}$ or $\mathrm{Y}$ from one side of the pseudo molecular ion
$\left[\mathrm{X}-(46)_{\mathrm{n}}-\mathrm{Y}+\mathrm{H}\right]^{+}$, and continues with $\mathrm{n}$ successive losses of a chain unit of mass 46 , to finally terminate on a fragment ion $\mathrm{XH}^{+}$or $\mathrm{YH}^{+}$, respectively, representing the opposite side of the molecule.

Attribution of the alkoxy group RO to either the starting group $\mathrm{X}$ or the end group $\mathrm{Y}$ of the pseudo molecular ion $\left[\mathrm{X}-(46)_{\mathrm{n}}-\mathrm{Y}+\mathrm{H}\right]^{+}$explains the two distinct fragmentation patterns in the MS/MS spectra of the type (a) oligomers formed 
from AVE. In Fig. 8, RO is for example proposed to be part of the starting group $\mathrm{X}$. The first fragmentation pattern, which conserves the RO group in the fragment ions, terminates with the fragment ion $\mathrm{XH}^{+}$, as shown on the right-hand side of Fig. 8. Application of this schema to the observed fragmentation pathway marked in violet colour (Table 3a and Figs. A4a, c and d) identifies the terminating fragment ions 127 (EVE), 141 (PVE) and 155 (the three isomers of BVE) as $\mathrm{XH}^{+}$and thus as the starting group $\mathrm{X}$ of the pseudo molecular ion $\left[\mathrm{X}-(46)_{\mathrm{n}}-\mathrm{Y}+\mathrm{H}\right]^{+}$. Consequently, in this example, the end group $\mathrm{Y}$ is represented by a neutral species of mass 64 , whose loss from the pseudo molecular ion $\left[\mathrm{X}-(46)_{\mathrm{n}}-\mathrm{Y}+\mathrm{H}\right]^{+}$ initiates the violet-coloured fragmentation pathway for type (a) oligomers from all AVE (Figs. A4a, c and d). The second fragmentation pattern, whose fragment ions do not contain the RO group and are identical for type (a) oligomers formed from different AVE, terminates on the fragment ion $\mathrm{YH}^{+}$, as shown on the left-hand side of Fig. 8. The starting group $\mathrm{X}$, which contains the RO group, is fragmented as neutral species from the pseudo molecular ion $\left[\mathrm{X}-(46)_{\mathrm{n}}-\mathrm{Y}+\mathrm{H}\right]^{+}$in the first step of this fragmentation pattern. Application of this scheme to the observed fragmentation pathways marked in red and green colours attributes their terminating fragment ions 85 and 99 to $\mathrm{YH}^{+}$, thus to the end group $\mathrm{Y}$ of the pseudo molecular ion $\left[\mathrm{X}-(46)_{\mathrm{n}}-\mathrm{Y}+\mathrm{H}\right]^{+}$. The starting group $\mathrm{X}$ is consequently represented by the neutral species first fragmented from the pseudomolecular ion $\left[\mathrm{X}-(46)_{\mathrm{n}}-\mathrm{Y}+\mathrm{H}\right]^{+}$, which are of masses 92 and 106 (EVE), 106 and 120 (PVE), and 120 and 134 (the three isomers of BVE) for the green- and redcoloured fragmentation pathways, respectively (Figs. A4a, c and d), and thus show the expected differences in units of $\Delta m / z=14$ according to the contained $\mathrm{RO}$ groups.

Separation of the oligomers by liquid chromatography proved the existence of at least four isomers of the pseudomolecular ion, as is shown in Fig. A3c for oligomers formed during the ozonolysis of EVE. The presence of these isomers explains the complexity of the MS/MS spectra, with at least nine identified fragmentation pathways (Table $3 a$ ) belonging to one of the two fragmentation patterns. The regularity of the different fragmentation pathways and the strict repetition of the two described fragmentation patterns suggest that the isomers follow the same structural principle. Therefore, in Fig. 8, isomers of the pseudomolecular ion $\left[\mathrm{X}-(46)_{\mathrm{n}}-\mathrm{Y}+\mathrm{H}\right]^{+}$ are symbolized by the addition of two more pseudomolecular structures $\left[\mathrm{A}-(46)_{\mathrm{n}}-\mathrm{Z}+\mathrm{H}\right]^{+}$and $\left[\mathrm{B}-(46)_{\mathrm{n}}-\mathrm{W}+\mathrm{H}\right]^{+}$. As is schematically shown in Fig. 8, MS/MS spectra thus contain the fragmentation pathways of all isomers $\left[\mathrm{X}-(46)_{\mathrm{n}}-\mathrm{Y}+\mathrm{H}\right]^{+}$, $\left[\mathrm{A}-(46)_{\mathrm{n}}-\mathrm{Z}+\mathrm{H}\right]^{+}$and $\left[\mathrm{B}-(46)_{\mathrm{n}}-\mathrm{W}+\mathrm{H}\right]^{+}$of a pseudomolecular ion according to the two fragmentation patterns depicted in Fig. 8 . Note that the proton ionizing the oligomer molecule is suggested in Fig. 8 to remain attached to the fragment ions. This is however an arbitrary decision for illustration purposes, as the determination of the exact fragmentation mechanism needs further investigation.
3.3.6 Elemental composition and minimum number $\mathrm{n}$ of the chain units 46 and 60

Possible elemental compositions of parent ions, fragment ions and fragmented neutral molecules were determinated from the $m / z$ values measured during MS/MS experiments. Resulting elemental compositions are given exemplarily in Figs. A4a-d for those ions and neutrals that are part of one of the three fragmentation pathways demonstrated in violet, red and green colours in the MS/MS spectra of oligomer (a) ions. Detailed results of the calculations are given for two of these pathways in Tables $4 \mathrm{a}$ and $\mathrm{b}$ : for the red-coloured fragmentation of the pseudomolecular ion 399 formed from EPE (see MS/MS spectrum in Fig. A4b) and for the violet-coloured fragmentation of the pseudomolecular ion 389 formed from PVE (MS/MS spectrum in Fig. A4c). Similar calculations from MS/MS spectra of several other pseudomolecular oligomeric ions formed from the diverse AVE and from $\mathrm{EPE}$, for the three green- red- and violet-coloured fragmentation pathways, as well as for other fragmentation pathways listed in Tables 3a and b, are given in Sadezky (2005) and show the reproducibility of these results.

Measured $m / z$ values allow a rather doubtless determination of the elemental compositions of the fragmented neutral molecules, in particular of the chain units 46 and 60 . Analysis of the calculated mass errors in Tables $4 \mathrm{a}$ and $\mathrm{b}$ show a strong and systematic preference of the elemental compositions $\mathrm{CH}_{2} \mathrm{O}_{2}$ (theoretical mass $46.0055 \mathrm{u}$ ) for the chain unit of mass 46 (AVE) and $\mathrm{C}_{2} \mathrm{H}_{4} \mathrm{O}_{2}$ (theoretical mass $60.0211 \mathrm{u}$ ) for the chain unit of mass 60 (EPE). The only other elemental compositions, which make chemical sense as neutral molecules in order to represent the chain units, $\mathrm{C}_{2} \mathrm{H}_{6} \mathrm{O}$ for mass 46 and $\mathrm{C}_{3} \mathrm{H}_{8} \mathrm{O}$ for mass 60 , usually show much larger mass errors.

Further work is needed to elucidate the structures of parent and fragment ions. For their chemical compositions, the elements $\mathrm{C}, \mathrm{H}$ and $\mathrm{O}$ and a single positive charge are taken into account. The fact that good fragmentation spectra are obtained from pseudomolecular ions during MS/MS experiments disagree with $\mathrm{Na}^{+}$adducts.

The existence of different isomers of the pseudomolecular ions further complicate a precise determination of the oligomer structures. In the MS/MS spectra, according to Fig. 8, fragment ions representing the respective starting and end groups $\mathrm{A}, \mathrm{B}, \mathrm{X}, \mathrm{Z}, \mathrm{W}$, and $\mathrm{Y}$ of all isomers of the pseudomolecular ion appear together. Even for the alkyl vinyl ethers AVE, for which the fragment ions containing the starting groups $\mathrm{X}, \mathrm{A}$, and $\mathrm{B}$ and those containing the end groups $\mathrm{Y}, \mathrm{Z}$ and $\mathrm{W}$ can be distinguished, fragment ions of different pathways cannot clearly be attributed to specific isomers so far. It is thus, for example, unknown whether two of the three fragmentation pathways discussed in detail in the sections above and demonstrated in violet, red and green colours (Table $3 \mathrm{a}$ and $\mathrm{b}$ and Figs. A4a-d) are complementary and 
Table 4. (a) Calculated elemental compositions of parent ions, fragment ions and fragmented neutral molecules for the red-coloured fragmentation pathway of the pseudomolecular oligomer ion 399 formed from EPE (see MS/MS spectrum in Fig. A4b).

\begin{tabular}{|c|c|c|c|c|}
\hline $\begin{array}{l}\text { Measured mass } \\
(\mathrm{u})\end{array}$ & $\begin{array}{c}\text { Elemental } \\
\text { composition }\end{array}$ & $\begin{array}{l}\text { Exact mass } \\
\text { (u) }\end{array}$ & $\begin{array}{l}\text { Absolute } \\
\text { mass error } \\
(\mathrm{mDa})\end{array}$ & $\begin{array}{c}\text { Relative } \\
\text { mass error } \\
(p p m)\end{array}$ \\
\hline \multirow{5}{*}{$\begin{array}{c}399,1556 \\
\text { parent ion } \\
{\left[X-[60]_{3}-Y+H\right]^{+}}\end{array}$} & $\mathrm{C}_{15} \mathrm{H}_{27} \mathrm{O}_{12}$ & 399,1497 & 5,8968 & 14,7732 \\
\hline & $\mathrm{C}_{16} \mathrm{H}_{31} \mathrm{O}_{11}$ & 399,18608 & $-30,4886$ & $-76,3828$ \\
\hline & $\mathrm{C}_{14} \mathrm{H}_{23} \mathrm{O}_{13}$ & 399,11331 & 42,2823 & 105,9293 \\
\hline & $\mathrm{C}_{17} \mathrm{H}_{35} \mathrm{O}_{10}$ & 399,22247 & $-66,8742$ & $-167,5389$ \\
\hline & $\mathrm{C}_{10} \mathrm{H}_{14}$ & 134,10955 & $-5,9505$ & $-44,3728$ \\
\hline \multirow{3}{*}{$\begin{array}{c}134,1036 \\
\text { initially } \\
\text { fragmented neutral } \\
X \text { or } Y\end{array}$} & $\mathrm{C}_{6} \mathrm{H}_{14} \mathrm{O}_{3}$ & 134,09429 & 9,3055 & 69,3905 \\
\hline & $\mathrm{C}_{9} \mathrm{H}_{10} \mathrm{O}$ & 134,07316 & 30,4349 & 226,9511 \\
\hline & $\mathrm{C}_{5} \mathrm{H}_{10} \mathrm{O}_{4}$ & 134,0579 & 45,6910 & 340,7144 \\
\hline \multirow{4}{*}{$\begin{array}{c}265,0520 \\
\text { fragment ion } \\
{\left[\mathrm{Y}-[60]_{3}+\mathrm{H}\right]^{+}} \\
\text {or }\left[\mathrm{X}-[60]_{3}+\mathrm{H}\right]^{+}\end{array}$} & $\mathrm{C}_{9} \mathrm{H}_{13} \mathrm{O}_{9}$ & 265,0554 & $-3,4086$ & $-12,8604$ \\
\hline & $\mathrm{C}_{8} \mathrm{H}_{9} \mathrm{O}_{10}$ & 265,01902 & 32,9768 & 124,4161 \\
\hline & $\mathrm{C}_{10} \mathrm{H}_{17} \mathrm{O}_{8}$ & 265,09179 & $-39,7942$ & $-150,1370$ \\
\hline & $\mathrm{C}_{11} \mathrm{H}_{21} \mathrm{O}_{7}$ & 265,12817 & $-76,1797$ & $-287,4137$ \\
\hline \multirow{3}{*}{$\begin{array}{c}60,0149 \\
\text { neutral } \\
\text { chain carrier } 60\end{array}$} & $\mathrm{C}_{2} \mathrm{H}_{4} \mathrm{O}_{2}$ & 60,02112 & $-6,2294$ & $-103,7982$ \\
\hline & $\mathrm{CO}_{3}$ & 59,98474 & 30,1560 & 502,4765 \\
\hline & $\mathrm{C}_{3} \mathrm{H}_{8} \mathrm{O}$ & 60,05751 & $-42,6149$ & $-710,0729$ \\
\hline \multirow{4}{*}{$\begin{array}{c}205,0326 \\
\text { fragment ion } \\
{\left[\mathrm{Y}-[60]_{2}+\mathrm{H}\right]^{+}} \\
\text {or }\left[\mathrm{X}-[60]_{2}+\mathrm{H}\right]^{+}\end{array}$} & $\mathrm{C}_{7} \mathrm{H}_{9} \mathrm{O}_{7}$ & 205,03427 & $-1,6792$ & $-8,1901$ \\
\hline & $\mathrm{C}_{6} \mathrm{H}_{5} \mathrm{O}_{8}$ & 204,99789 & 34,7062 & 169,2714 \\
\hline & $\mathrm{C}_{8} \mathrm{H}_{13} \mathrm{O}_{6}$ & 205,07066 & $-38,0647$ & $-185,6518$ \\
\hline & $\mathrm{C}_{9} \mathrm{H}_{17} \mathrm{O}_{5}$ & 205,10705 & $-74,4503$ & $-363,1134$ \\
\hline \multirow{3}{*}{$\begin{array}{c}60,0202 \\
\text { neutral } \\
\text { chain carrier } 60\end{array}$} & $\mathrm{C}_{2} \mathrm{H}_{4} \mathrm{O}_{2}$ & 60,02112 & $-0,9294$ & $-15,4854$ \\
\hline & $\mathrm{CO}_{3}$ & 59,98474 & 35,4560 & 590,7357 \\
\hline & $\mathrm{C}_{3} \mathrm{H}_{8} \mathrm{O}$ & 60,05751 & $-37,3149$ & $-621,7066$ \\
\hline \multirow{4}{*}{$\begin{array}{c}145,0178 \\
\text { fragment ion } \\
{[\mathrm{Y}-[60]+\mathrm{H}]^{+}} \\
\text {or }[\mathrm{X}-[60]+\mathrm{H}]^{+}\end{array}$} & $\mathrm{C}_{5} \mathrm{H}_{5} \mathrm{O}_{5}$ & 145,0131 & 4,6501 & 32,0661 \\
\hline & $\mathrm{C}_{6} \mathrm{H}_{9} \mathrm{O}_{4}$ & 145,0495 & $-31,7353$ & $-218,8367$ \\
\hline & $\mathrm{C}_{4} \mathrm{HO}_{6}$ & 144,9768 & 41,0356 & 282,9690 \\
\hline & $\mathrm{C}_{7} \mathrm{H}_{13} \mathrm{O}_{3}$ & 145,0859 & $-68,1208$ & $-469,7395$ \\
\hline \multirow{3}{*}{$\begin{array}{c}60,0247 \\
\text { neutral } \\
\text { chain carrier } 60\end{array}$} & $\mathrm{C}_{2} \mathrm{H}_{4} \mathrm{O}_{2}$ & 60,02112 & 3,5705 & 59,4848 \\
\hline & $\mathrm{C}_{3} \mathrm{H}_{8} \mathrm{O}$ & 60,05751 & $-32,8149$ & $-546,6909$ \\
\hline & $\mathrm{CO}_{3}$ & 59,98474 & 39,9560 & 665,6606 \\
\hline \multirow{3}{*}{$\begin{array}{c}84,9931 \\
\text { fragment ion } \\
{[\mathrm{Y}+\mathrm{H}]^{+} \text {or }[\mathrm{X}+\mathrm{H}]^{+}}\end{array}$} & $\mathrm{C}_{3} \mathrm{HO}_{3}$ & 84,9920 & 1,0796 & 12,7023 \\
\hline & $\mathrm{C}_{4} \mathrm{H}_{5} \mathrm{O}_{2}$ & 85,0284 & $-35,3058$ & $-415,3945$ \\
\hline & $\mathrm{C}_{5} \mathrm{H}_{9} \mathrm{O}$ & 85,06479 & $-71,6914$ & $-843,4914$ \\
\hline
\end{tabular}

generated by the same isomer, or if all three pathways originate from different isomers.

MS/MS experiments allow to determine the minimum number of chain units $\mathrm{n}$ comprised in an oligomer molecule. $\mathrm{n}$ is derived from the number of successive losses of the chain unit as a neutral molecule which are directly observed in the MS/MS spectra. Its values are given in Table 2 and in the MS spectra of the oligomers in Figs. A1a-d, and are between 2 and 9 for most oligomers. The most abundant pseudomolecular ions contain 3 to 4 chain units.
Table 4. (b) Calculated elemental compositions of parent ions, fragment ions and fragmented neutral molecules for the violet-coloured fragmentation pathway of the pseudomolecular oligomer ion 389 formed from PVE (see MS/MS spectrum in Fig. A4c).

\begin{tabular}{|c|c|c|c|c|}
\hline $\begin{array}{l}\text { Measured mass } \\
\text { (u) }\end{array}$ & $\begin{array}{c}\text { Elemental } \\
\text { composition }\end{array}$ & $\begin{array}{l}\text { Exact mass } \\
\text { (u) }\end{array}$ & $\begin{array}{c}\text { Absolute } \\
\text { mass error } \\
(\mathrm{mDa})\end{array}$ & $\begin{array}{c}\text { Relative } \\
\text { mass error } \\
(\mathrm{ppm})\end{array}$ \\
\hline \multirow{4}{*}{$\begin{array}{c}389,0984 \\
\text { parent ion } \\
{\left[X-[46]_{4}-Y+H\right]^{+}}\end{array}$} & $\mathrm{C}_{12} \mathrm{H}_{21} \mathrm{O}_{14}$ & 389,09258 & 5,8177 & 14,9519 \\
\hline & $\mathrm{C}_{13} \mathrm{H}_{25} \mathrm{O}_{13}$ & 389,12896 & $-30,5677$ & $-78,5603$ \\
\hline & $\mathrm{C}_{11} \mathrm{H}_{17} \mathrm{O}_{15}$ & 389,05619 & 42,2033 & 108,4641 \\
\hline & $\mathrm{C}_{14} \mathrm{H}_{29} \mathrm{O}_{12}$ & 389,16535 & $-66,9532$ & $-172,0725$ \\
\hline \multirow{4}{*}{$\begin{array}{c}64,0187 \\
\text { initially } \\
\text { fragmented } \\
\text { neutral } Y\end{array}$} & $\mathrm{CH}_{4} \mathrm{O}_{3}$ & 64,01604 & 2,6559 & 41,4866 \\
\hline & $\mathrm{C}_{5} \mathrm{H}_{4}$ & 64,0313 & $-12,6001$ & $-196,8199$ \\
\hline & $\mathrm{C}_{4} \mathrm{O}$ & 63,99491 & 23,7853 & 371,5376 \\
\hline & $\mathrm{O}_{4}$ & 63,97965 & 39,0414 & 609,8443 \\
\hline \multirow{3}{*}{$\begin{array}{c}325,0797 \\
\text { fragment ion } \\
{\left[X-[46]_{4}+H\right]^{+}}\end{array}$} & $\mathrm{C}_{11} \mathrm{H}_{17} \mathrm{O}_{11}$ & 325,07653 & 3,1618 & 9,7263 \\
\hline & $\mathrm{C}_{12} \mathrm{H}_{21} \mathrm{O}_{10}$ & 325,11292 & $-33,2236$ & $-102,2014$ \\
\hline & $\mathrm{C}_{10} \mathrm{H}_{13} \mathrm{O}_{12}$ & 325,04015 & 39,5473 & 121,6542 \\
\hline \multirow{2}{*}{$\begin{array}{c}46,0064 \\
\text { neutral } \\
\text { chain carrier } 46\end{array}$} & $\mathrm{CH}_{2} \mathrm{O}_{2}$ & 46,00547 & 0,9206 & 20,0111 \\
\hline & $\mathrm{C}_{2} \mathrm{H}_{6} \mathrm{O}$ & 46,04186 & $-35,4648$ & $-770,8684$ \\
\hline \multirow{3}{*}{$\begin{array}{c}279,0733 \\
\text { fragment ion } \\
{\left[X-[46]_{3}+H\right]^{+}}\end{array}$} & $\mathrm{C}_{10} \mathrm{H}_{15} \mathrm{O}_{9}$ & 279,07105 & 2,2412 & 8,0309 \\
\hline & $\mathrm{C}_{11} \mathrm{H}_{19} \mathrm{O}_{8}$ & 279,10744 & $-34,1443$ & $-122,3486$ \\
\hline & $\mathrm{C}_{9} \mathrm{H}_{11} \mathrm{O}_{10}$ & 279,03467 & 38,6267 & 138,4104 \\
\hline \multirow{2}{*}{$\begin{array}{c}46,0093 \\
\text { neutral } \\
\text { chain carrier } 46\end{array}$} & $\mathrm{CH}_{2} \mathrm{O}_{2}$ & 46,00547 & 3,8206 & 83,0406 \\
\hline & $\mathrm{C}_{2} \mathrm{H}_{6} \mathrm{O}$ & 46,04186 & $-32,5648$ & $-707,7890$ \\
\hline \multirow{3}{*}{$\begin{array}{c}233,0640 \\
\text { fragment ion } \\
{\left[X-[46]_{2}+H\right]^{+}}\end{array}$} & $\mathrm{C}_{9} \mathrm{H}_{13} \mathrm{O}_{7}$ & 233,06557 & $-1,5794$ & $-6,7767$ \\
\hline & $\mathrm{C}_{8} \mathrm{H}_{9} \mathrm{O}_{8}$ & 233,02919 & 34,806 & 149,341 \\
\hline & $\mathrm{C}_{10} \mathrm{H}_{17} \mathrm{O}_{6}$ & 233,10196 & $-37,9649$ & $-162,8945$ \\
\hline \multirow{2}{*}{$\begin{array}{c}45,9996 \\
\text { neutral } \\
\text { chain carrier } 46\end{array}$} & $\mathrm{CH}_{2} \mathrm{O}_{2}$ & 46,00547 & $-5,8793$ & $-127,8132$ \\
\hline & $\mathrm{C}_{2} \mathrm{H}_{6} \mathrm{O}$ & 46,04186 & $-42,2648$ & $-918,8097$ \\
\hline \multirow{3}{*}{$\begin{array}{c}187,0644 \\
\text { fragment ion } \\
{[X-[46]+H]^{+}}\end{array}$} & $\mathrm{C}_{8} \mathrm{H}_{11} \mathrm{O}_{5}$ & 187,0601 & 4,2999 & 22,9863 \\
\hline & $\mathrm{C}_{9} \mathrm{H}_{15} \mathrm{O}_{4}$ & 187,09648 & $-32,0855$ & $-171,521$ \\
\hline & $\mathrm{C}_{7} \mathrm{H}_{7} \mathrm{O}_{6}$ & 187,02371 & 40,6854 & 217,4937 \\
\hline \multirow{2}{*}{$\begin{array}{c}46,0120 \\
\text { neutral } \\
\text { chain carrier } 46\end{array}$} & $\mathrm{CH}_{2} \mathrm{O}_{2}$ & 46,00547 & 6,5206 & 141,716 \\
\hline & $\mathrm{C}_{2} \mathrm{H}_{6} \mathrm{O}$ & 46,04186 & $-29,8648$ & $-649,0671$ \\
\hline \multirow{3}{*}{$\begin{array}{c}141,0524 \\
\text { fragment ion } \\
{[X+H]^{+}}\end{array}$} & $\mathrm{C}_{7} \mathrm{H}_{9} \mathrm{O}_{3}$ & 141,05462 & $-2,2207$ & $-15,7437$ \\
\hline & $\mathrm{C}_{6} \mathrm{H}_{5} \mathrm{O}_{4}$ & 141,01823 & 34,1648 & 242,2127 \\
\hline & $\mathrm{C}_{8} \mathrm{H}_{13} \mathrm{O}_{2}$ & 141,0910 & $-38,6062$ & $-273,7001$ \\
\hline
\end{tabular}

\section{Discussion}

It might be essential to consider the role of the Criegee Intermediate $(\mathrm{CI})$ in the formation of oligomers. Indeed, the linking chain units observed in this study of the different oligomers have the same elementary composition as the CIs: $\mathrm{CH}_{2} \mathrm{O}_{2}\left(=\mathrm{CH}_{2} \mathrm{OO}\right.$ for $\left.\mathrm{C}_{1}-\mathrm{CI}\right)$ of mass 46 for the alkyl vinyl ethers (AVE) and $\mathrm{C}_{2} \mathrm{H}_{4} \mathrm{O}_{2}\left(=\mathrm{CH}_{3} \mathrm{CHOO}\right.$ for $\left.\mathrm{C}_{2}-\mathrm{CI}\right)$ of mass 60 for ethyl propenyl ether (EPE).

The structure of the oligomer, which is schematically shown in Fig. 8, is deduced from the fragmentation pattern of the main ions, obtained by ESI(+)/Q-TOF MS/MS, as is displayed in Figs. A4a-d. The fragments, whose successive 
<smiles>[Y]C(C)OOC([Y])CC</smiles>

$\Delta \mathrm{m} / \mathrm{z}=46(\mathrm{AVE})$

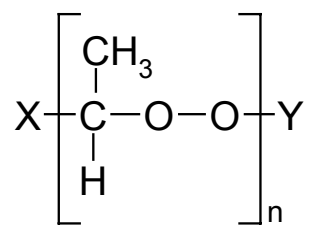

$\Delta \mathbf{m} / \mathbf{z}=60(\mathrm{EPE})$

Fig. 9. Oligoperoxidic structure attributed to the oligomers formed during ozonolysis of (a) Alkyl vinyl ethers (AVE) (b) Ethyl propenyl ether (EPE).

and systematic loss is observed in the fragmentation spectra, are neutral species with the chemical compositions $\mathrm{CH}_{2} \mathrm{O}_{2}$ (mass 46) and $\mathrm{C}_{2} \mathrm{H}_{4} \mathrm{O}_{2}$ (mass 60), respectively for the AVE and EPE. Based on these observations, we suggest that the oligomer might have the following basic structure of an oligoperoxide shown in Fig. 9:

Moreover, the ozonolysis experiments performed in the presence of $\mathrm{HCOOH}$, which is know to be an efficient Criegee Intermediate scavenger, have shown that the yield of SOA formation was drastically reduced, eventually suppressed, and that oligomers in detectable quantities are not formed. SOA formation is also strongly reduced in the presence of $\mathrm{H}_{2} \mathrm{O}$ (Sadezky, 2005). Consequently, this reaction obviously competes with known reactions of the stabilized CI (SCI) with $\mathrm{HCOOH}$ or $\mathrm{H}_{2} \mathrm{O}$, which lead to the formation of small gaseous peroxide compounds (Calvert et al., 2000). Oligoperoxide formation is thus another, so far unknown reaction of stabilized SCIs in the gas phase leading to SOA formation.

The decrease of SOA yields observed during vinyl ether ozonolysis experiments in the presence of cyclohexane so far cannot be explained in a conclusive manner. A decrease of SOA yields in the presence of cyclohexane as an $\mathrm{OH}$ scavenger was also observed for cyclohexene ozonolysis by Keywood et al. (2004), while Docherty and Ziemann (2003) reported the opposite trend for SOA yields from $\beta$ pinene ozonolysis. Keywood et al. (2004) and Docherty and Ziemann (2003) explained these observations by a decrease of the ratio [hydroperoxy radicals]/[organic peroxyradicals] in the presence of cyclohexane. According to Keywood et al. (2004), this ratio might have an influence on the production pathways and chemistry of acylperoxy radicals, which had been suggested in earlier studies (Koch et al., 2000) to be key intermediates for the formation of low-volatile reaction products (diacids and peradics) from monoterpene and cycloalkene ozonolysis. However, a similar contribution of acyl radicals to the formation of high-molecular reaction products in the case of alkyl vinyl ether ozonolysis is very unlikely, as the known gas-phase reaction mechanisms only lead to formation of HCO and ROCO radicals (Sadezky, 2005, Klotz et al., 2004), which are expected to be unstable and to directly decompose by reaction with $\mathrm{O}_{2}$. Therefore, a reaction mechanism different from that suggested by Keywood et al. (2004) for cyclohexene ozonolysis should be responsible for the observed effect of cyclohexane on the SOA yields from vinyl ether ozonolysis, which is however so far unknown.

Oligomers have long time been recognized to be significant products of the ozonolysis in solutions (Barton et al., 2004; Lockley et al., 2001; and references therein). Early studies by Criegee (1957) speculated on the products of the ozonolysis incorporated in the oligomeric structures, namely the CI, also called carbonyl oxide. Lockley et al. (2001) investigated the ozonolysis of tetramethylethylene (TME) at $-60^{\circ} \mathrm{C}$ and identified acetone cyclic di- and triperoxides, and substantial amounts of oligomeric peroxides of acetone carbonyl oxide. Both linear and cyclic oligomeric peroxides were inferred from GC-MS analysis. Also recently Barton et al. (2004) performed the ozonolysis of tetramethylethylene (TME) in pentane as a nonparticipating solvent at $-60^{\circ} \mathrm{C}$ yielding predominantly oligoperoxides with $m / z$ up to $900 \mathrm{u}$, as identified by ESI/MS under soft ionization conditions. The peroxidic chain link of the mass peaks was of mass 74 , which corresponds to the mass of the acetone carbonyl oxide $\left(\mathrm{CH}_{3}\right)_{2} \mathrm{COO}$, thus the $\mathrm{CI}$ formed in the ozonolysis of TME (Fig. 10). Up to 12 chain units were observed for different oligoperoxides. Moreover, these oligomeric compounds were found to be thermally stable when extracted and refluxed in methanol for a few hours (Barton et al., 2004).

In liquid phase, the formation of small peroxidic compounds in the presence of protonic solvents or additives, such as $\mathrm{H}_{2} \mathrm{O}$, alcohols and organic acids, is also well known (e.g. Bunnelle, 1991; Thamm et al., 1996). In the liquidphase ozonolysis of TME, oligoperoxide formation was only observed in non-protonated solvents (pentane) by Barton et al. (2004). The suppression of SOA and oligomer formation in the presence of $\mathrm{HCOOH}$ observed in the gas phase in this work is in analogy to the liquid-phase chemistry.

It is to be concluded that the CIs play a pertinent role in the oligomerization also in the gas phase. The mechanism of formation of the oligoperoxides found in the ozonolysis of enol ethers remains an enigma, since this type of repetitive chain structure involving $\mathrm{CH}_{2} \mathrm{OO}$ and $\mathrm{CH}_{3} \mathrm{CHOO}$ units has not been observed previously in gas phase reactions.

Several studies have reported the formation of SOA in the gas phase oxidation of VOC and identified polymerization reactions in the presence (Tolocka et al., 2004; Gao et al., 2004) and absence (Kalberer et al., 2004; Ziemann, 2002, 2003; Zahardis et al., 2005) of preexisting acid seed 


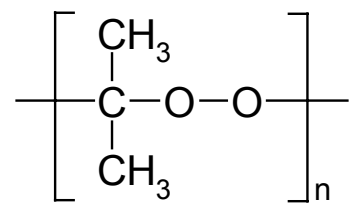

$\Delta \mathrm{m} / \mathrm{z}=74$ (TME, liquid phase ozonolysis)

Fig. 10. Oligoperoxides formed during liquid phase ozonolysis of tetramethylethylene (TME) (Barton et al., 2004).

aerosols. Most of these studies invoked oligomerization by acid-catalysed aldol condensation and $\mathrm{gem}$-diol formation of main carbonyl products of the ozonolysis reaction. Tolocka et al. (2004) reported oligomers in the SOA produced in the ozonolysis of $\alpha$-pinene, which are formed from such reactions of pinonaldehyde. Gao et al. (2004) observed formation of large oligomers (up to $m / z 1600$ ) in the ozonolysis of a series of cyclic alkenes, and reported similar condensation reactions among carbonyl reaction products. Kalberer et al. (2004) detected oligomers in SOA formed during photooxidation of 1,3,5-trimethylbenzene, and attributed them to hydration-condensation reactions involving the main reaction products glyoxal and methylglyoxal. Peroxidic products were taken into consideration by other previous studies: Ziemann (2002) suggested the formation of diacylperoxides that act as nucleating agents in the ozonolysis of cyclic alkenes. A mechanism was presented involving the cross reaction of acylperoxy radicals, formed upon isomerisation and decomposition of excited Criegee Intermediates in air. In the presence of alcohols Ziemann (2003) invoked the formation of alkoxyhydroperoxy aldehydes, which were generated from the reaction of SCI with alcohols, and subsequently undergo intermolecular reaction to form cyclic peroxyhemiacetals. The only other study that so far reported reactions among Criegee Intermediates was recently published by Zahardis et al. (2005). The authors studied the ozonolysis of oleic acid and identified secondary ozonides and cyclic geminal diperoxides, the latter being formed through the recombination of two SCI.

\section{Conclusion}

In this work, we investigated secondary organic aerosol (SOA) formation from the gas phase ozonolysis of enol ethers. In spite of the fact that these compounds consist of only 5 to 7 carbon atoms, significant SOA formation was observed. Chemical analysis of the formed SOA allowed us to suggest a new reaction mechanism for new SOA particle formation: the oligomerization of Criegee Intermediates leading to the formation of oligoperoxidic chains with molecular weights up to 300 to $500 \mathrm{u}$. The suggested mechanism is in agreement with the formation of oligoperoxidic compounds from Criegee Intermediates, which was observed during liquid phase ozonolysis in earlier studies. Thus, in this work, we report the first observation of a similar reaction during gas phase ozonolysis. It is suggested that in the gas phase, oligoperoxides are formed from reactions of stabilized Criegee Intermediates, the detailed mechanisms of these reactions, however, are so far unknown and need further investigation.

Earlier studies have shown that the main tropospheric degradation mechanisms of unsaturated ethers are their reactions with ozone and $\mathrm{OH}$ radicals (Thiault et al., 2002). The present study shows that mixing ratios of a few hundred $\mathrm{ppb}$ of enol ether and ozone are sufficient for significant formation of SOA. However, stabilized Criegee Intermediates are expected to react mainly with water vapour in the troposphere to form gaseous hydroxyhydroperoxides (Calvert et al., 2000), a reaction that has been shown to compete with other known reactions of stabilized Criegee Intermediates as well as with SOA formation (Sadezky, 2005; Bonn et al., 2002). The relevance of the observed oligoperoxide formation for SOA formation in the atmosphere has thus to be further investigated. In contrast to the other mechanisms of oligomer formation suggested to contribute to tropospheric SOA formation, which always involve heterogeneous or multiphase reactions on preexisting aerosol particles (e.g. Tolocka et al., 2004; Gao et al., 2004), the oligoperoxide formation observed in the present work takes place in the gas phase and might then initiate nucleation, thus leading to the observed new SOA particle formation.

Edited by: M. Kulmala

\section{References}

Barton, M., Ebdon, J. R., Foster, A. B., and Rimmer, S.: Ozonolysis of tetramethylethylene: Characterization of cyclic and openchain oligoperoxidic products, J. Org. Chem., 69, 6967-6973, 2004.

Bonn, B., Schuster, G., and Moortgat, G. K.: Influence of water vapor on the process of new particle formation during monoterpene ozonolysis, J. Phys. Chem. A, 106, 2869-2881, 2002.

Bunnelle, W. H.: Preparation, properties, and reactions of carbonyl oxides, Chem. Rev., 91, 335-362, 1991.

Calvert, J. G., Atkinson R., Kerr J. A., Madronich S., Moortgat G. K., Wallington, T. J., and Yarwood, G.: The mechanisms of atmospheric oxidation of the alkenes, Oxford University Press, 2000.

Chaimbault, P., Elfakir, C., and Lafosse, M.: Comparison of the retention behavior of polyethoxylated alcohols on porous graphitic carbon and polar as well as apolar-bonded silica phases, J. Chromatogr. A, 797, 83-91, 1998.

Criegee, R.: The course of ozonation of unsaturated compounds, Record Chem. Prog., 18, 111-120, 1957. 
Finlayson, B. J., Pitts, J. N., and Akimoto, H.: Production of vibrationnally excited $\mathrm{OH}$ in chemiluminescent ozone-olefin reactions, Chem. Phys. Lett., 12, 495-498, 1972.

Docherty, K. S. and Ziemann, P. J.: Effects of stabilized Criegee Intermediate and $\mathrm{OH}$ radical scavengers on aerosol formation from reactions of $\beta$-pinene with $\mathrm{O}_{3}$, Aerosol Sci. Technol., 37, 877891, 2003.

Gao, S., Nga, L. N., Keywood, M., Varutbangkul, V., Bahreini, R., Nenes, A., He, J., Yoo, K. Y., Beauchamp, J. L., Hodyss, R. P., Flagan, R. C., and Seinfeld, J. H.: Particle phase acidity and oligomer formation in secondary organic aerosol, Env. Sci. Technol., 38, 6582-6589, 2004.

George, C., Sidebottom, H., Mellouki, A., Barnes, I., Pilling, M., Herrmann, H., Wortham, H., Kirchner, F., Wirtz, K., and Zetzsch, C.: Multiphase chemistry of oxygenated species in the atmosphere, Final report, EVK2-CT-2001-00114, July, 2005.

Horie, O., Neeb, P., and Moortgat, G. K.: The reactions of the Criegee Intermediate $\mathrm{CH}_{3} \mathrm{CHOO}$ in the gas-phase ozonolysis of 2-butene isomers, Int. J. Chem. Kin., 29, 461-468, 1997.

Kalberer, M., Paulsen, D., Sax, M., Steinbacher, M., Dommen, J., Prevot, A. S. H., Fisseha, R., Weingartner, E., Frankevich, V., Zenobi, R., and Baltensperger, U.: Identification of polymers as major components of atmospheric organic aerosols, Science, 303, 1659-1662, 2004.

Keul, H., Choi, H. S., and Kuczkowski, R. L.: Ozonolysis of enol ethers. Formation of 3-alkoxy-1,2-dioxolanes by concerted addition of a carbonyl oxide to an enol ether, J. Org. Chem., 50, 3365-3371, 1985.

Keywood, M. D., Kroll, J. H., Varutbangkul, V., Bahreini, R., Flagan, R. C. and Seinfeld, J. H.: Secondary organic aerosol formation from cyclohexene ozonolysis: Effect of $\mathrm{OH}$ scavenger and the role of radical chemistry, Environ. Sci. Technol., 38, 33433350, 2004.

Klotz, B., Barnes, I., and Imamura, T.: Product study of the gasphase reactions of $\mathrm{O}_{3}, \mathrm{OH}$ and $\mathrm{NO}_{3}$ radicals with methyl vinyl ether, Phys. Chem. Chem. Phys., 6, 1725-1734, 2004.

Koch, S., Winterhalter, R., Uherek, E., Kolloff, A., Neeb, P., and Moortgat, G. K.: Formation of new particles in the gas-phase ozonolysis of monoterpenes, Atmos. Environ., 34, 4031-4042, 2000.

Lockley, J. E., Ebdon, J. R., Rimmer, S., and Tabner, B. J.: Polymerization of methyl methacrylate initiated by ozonates of tetramethylethene, Polymer, 42, 1797-1807, 2001.

Neeb, P., Horie, O., and Moortgat, G. K.: The ethene-ozone reaction in the gas phase, J. Phys. Chem. A, 102, 6778-6785, 1998.

Odum, J. R., Hoffmann, T., Bowman, F., Collins, D., Flagan, R. C., and Seinfeld, J. H.: Gas/particle partitioning and secondary organic aerosol yields, Environ. Sci. Technol., 30, 2580-2585, 1996.
Pankow, J. F.: An absorption model of gas/particle partitioning involved in the formation of secondary organic aerosol, Atmos. Environ., 28, 189-193, 1994.

Römpp, A.: Analysis of organic compounds in atmospheric aerosol by liquid chromatography-high resolution mass spectrometry (LC/MS/MS-TOF): method development and applications, $\mathrm{PhD}$ thesis, Johannes-Gutenberg University of Mainz, 2003.

Sadezky, A.: Ozonolyse d'éthers insaturés: Etudes des mécanismes en phase gazeuse et de la formation d'aérosol organique secondaire, PhD thesis, University of Orléans, 2005.

Seinfeld, J. H. and Pandis, S. N.: Atmospheric chemistry and physics: From air pollution to climate change, John Wiley \& Sons Inc., New York, p. 738, 1998.

Seinfeld, J. H. and Pankow, J. F.: Organic atmospheric particular material, Annu. Rev. Phys. Chem., 54, 121-140, 2003.

Thamm, J., Wolff, S., Turner, W. V., Gäb, S., Thomas, W., Zabel, F., Fink, E. H., and Becker, K. H.: Proof of the formation of hydroperoxymethyl formate in the ozonolysis of ethene: Synthesis and FTIR spectra of the authentic compound, Chem. Phys. Lett., 258, 155-158, 1996.

Thiault, G., Thévenet, R., Mellouki, A., and Le Bras, G.: OH and $\mathrm{O}_{3}$ initiated oxidation of ethyl vinyl ether, Phys. Chem. Chem. Phys., 4, 613-619, 2002.

Tolocka, M. P., Jang, M., Ginter, J. M., Cox, F. J., Kamens, R. M., and Johnston, M. V.: Formation of oligomers in secondary organic aerosol, Environ. Sci. Technol., 38, 1428-1434, 2004.

Winterhalter, R., Neeb, P., Grossmann, D., Kolloff, A., Horie, O., and Moortgat, G. K.: Products and mechanism of the gas phase reaction of ozone with $\beta$-pinene, J. Atmos. Chem., 35, 165-197, 2000.

Zahardis, J., LaFranchi, B. W., and Petrucci, G. A.: Photoelectron resonance capture ionization-aerosol mass spectrometry of the ozonolysis products of oleic acid particles: Direct measure of higher molecular weight oxygenates, J. Geophys. Res., 110, D08307, doi:10.1029/2004JD005336, 2005.

Ziemann, P. J.: Evidence for low-volatility diacyl peroxides as a nucleating agent and major component of aerosol formed from reactions of $\mathrm{O}_{3}$ with cyclohexene and homologous compounds, J. Phys. Chem. A, 106, 4390-4402, 2002.

Ziemann, P. J.: Formation of alkoxyhydroperoxy aldehydes and cyclic peroxyhemiacetals from reactions of cyclic alkenes with $\mathrm{O}_{3}$ in the presence of alcohols, J. Phys. Chem. A, 107, 20482060, 2003. 